\title{
From conceptual design to process design optimization: a review on flowsheet synthesis
}

\author{
Ludovic Montastruc ${ }^{1, *}$, Ségolène Belletante ${ }^{2}$, Alexandre Pagot $^{2}$, Stéphane Negny ${ }^{1}$, and Ludovic Raynal ${ }^{2}$ \\ ${ }^{1}$ Université de Toulouse, Laboratoire de Génie Chimique UMR CNRS/INPT/UPS, allée Emile Monso, \\ 31432 Toulouse Cedex, France \\ ${ }^{2}$ IFP Energies nouvelles, Rond-point de l'échangeur de Solaize, BP 3, 69360 Solaize, France
}

Received: 1 April 2019 / Accepted: 3 September 2019

\begin{abstract}
This paper presents the authors' perspectives on some of the open questions and opportunities in Process Systems Engineering (PSE) focusing on process synthesis. A general overview of process synthesis is given, and the difference between Conceptual Design (CD) and Process Design (PD) is presented using an original ternary diagram. Then, a bibliometric analysis is performed to place major research team activities in the latter. An analysis of ongoing work is conducted and some perspectives are provided based on the analysis. This analysis includes symbolic knowledge representation concepts and inference techniques, i.e., ontology, that is believed to become useful in the future. Future research challenges that process synthesis will have to face, such as biomass transformation, shale production, response to spaceflight demand, modular plant design, and intermittent production of energy, are also discussed.
\end{abstract}

$\begin{array}{ll}\text { Abbreviations } \\ \text { CD } & \text { Conceptual Design } \\ \text { GWP } & \text { Global Warming Potential } \\ \text { ICAS } & \text { Integrated Computer-Aided System } \\ \text { LCA } & \text { Life Cycle Analysis } \\ \text { MA } & \text { Memetic Algorithm } \\ \text { MILP } & \text { Mixed Integer Linear Programming } \\ \text { MINLP } & \text { Mixed Integer Non Linear Programming } \\ \text { MP2 } & \text { Multi Physics Multi Purpose } \\ \text { NLP } & \text { Non Linear Programming } \\ \text { PD } & \text { Process Design }\end{array}$

\section{Introduction}

Process synthesis is a dynamic research domain widely explored by the Process Systems Engineering (PSE) community. This topic was first put forth 60 years ago as mentioned by Stephanopoulos and Reklaitis (2011) in their paper on the historical development of PSE. Westerberg (2004), in his retrospective on design and process synthesis, has defined process synthesis as the part of engineering "where one invents the structure and operating levels for

\footnotetext{
* Corresponding author: ludovic.montastruc@ensiacet.fr
}

a new chemical manufacturing process." Process synthesis applies to both the design of a completely new process flowsheet and the retrofit and optimization of an existing process. Furthermore, process synthesis is the assembly and interconnection of unit operations into a process network involving different physical and chemical phenomena to transform a material into desired products for given energy inputs with the goal of optimizing either economic, environmental, and/or social objectives (Chen and Grossmann, 2017). As already stated in the review by Cremaschi (2015) and completed by a recent search in journal articles and progressing databases (as discussed in Sect. 2), there is an exponential increase in the total number of publications on process synthesis over the past decades. This trend will be further increased due to the future research challenges that process synthesis will face, e.g., biomass transformation, shale production, response to spaceflight demands, modular plant design, and intermittent production of energy. These challenges will be further discussed in the last section of this article.

According to previous reviews on this research field (Cremaschi, 2015; Westerberg, 2004), the process synthesis community is mainly focused on four major topics: reactor networks, separation sequences, heat exchanger networks, and flowsheet synthesis. The present review does not intend to be exhaustive, as it focuses more specifically on flowsheet synthesis. For other topics, readers can refer to the excellent reviews and perspectives mentioned above. Chronologically, the two main categories of approaches developed to address 
the process synthesis issues are hierarchical decomposition based on heuristics and mathematical programming attributed to huge advances in optimization methods. The current methods are mostly based on the mathematical programming approach to (1) incorporate the interactions between different design levels, (2) find the optimal design with respect to one or several objectives, and (3) avoid elimination of new promising process alternatives because heuristics are based on previous observation process flowsheets. Generally, such approaches are broken down into three stages: creation of a superstructure that gathers all process alternatives, translation of these alternatives into a relevant optimization model, and development of an optimization algorithm to solve the model. Concerning the last two stages, Chen and Grossmann (2017) recently discussed the progress to date and the future progress in mathematical programming concerning global and robust optimization methods. They reviewed key concepts in optimizationbased conceptual design, namely superstructure representations, multilevel models, optimization methods, and modeling environments. A brief review of the synthesis of major subsystems and flowsheets is also presented. Therefore, the present article does not deal with those stages.

The purpose of this paper is to analyze and discuss the novel and powerful design methods developed by the PSE community and to provide some perspectives and opportunities in process synthesis focusing on flowsheet synthesis. The selection of flowsheet synthesis is motivated by the potential of this area, and by the future challenges and opportunities of this research domain owing to environmental concerns, industrial and economic context, raw material and product diversification, energy saving, and technological innovation. As aforementioned, the latest reviews are more focused on the other process synthesis topics and on mathematical optimization. Consequently, the present contribution is a complement to the previous articles.

This article is divided into four parts. Section 2 provides a general overview of process synthesis and presents the difference between Conceptual Design (CD) and Process Design (PD) using an original ternary diagram. A bibliometric analysis is performed to place major research team activities in this ternary diagram. In Section 3, a description of main identified methodologies is presented. Section 4 is dedicated to an analysis of ongoing works and some perspectives are proposed.

\section{Perspective of the problem}

\subsection{General overview}

The development of an industrial process is a succession of steps that focus on a wide range of scales keeping in mind that the smaller the scale, the more detailed and complex the description of the process ( $\mathrm{Li}$ and Kraslawski, 2004). The considered scales depend on the objectives and scope of the study and the hypothesis or available information. For example, in their approach, Zondervan et al. (2011) focused on three successive scales, i.e., the unit operation scale, unit scale, and plant scale, because their objective was to find the optimal processing route within a set of alternatives as exhaustively as possible.

Those scales can be expanded in both directions. When considering large scales, there is a new trend to go beyond the process scale, expand the vision of process synthesis, and better integrate the process into its ecosystem. For example, Kuznetsova et al. (2016) and Ramos et al. (2016) have dealt with a problem on the synthesis of an eco-industrial park, and Ekşioğlu et al. (2009) and Tay et al. (2013) with the scale of the supply chain. In contrast, when considering small scales, after having integrated the molecular scale (Belletante et al., 2016; Marrero and Gani, 2001) to integrate the thermodynamic calculations and evaluate the feasibility of each processing route, some recent studies went even further by considering the particle scale to determine more precisely the process feasibility and efficiency (Barone et al., 2017; Xia, 2017).

In the present study dedicated to process synthesis, four successive levels are considered as of major interest for the process engineer: plant design level, conceptual design level, process design level, and equipment design level. These levels are illustrated in Figure 1 for the specific case of a chemical plant. On the left side, the plant design level corresponds to the chemical plant at a larger scale. A unit cluster or a specific unit of the plant design level is detailed in the next square, which illustrates the conceptual design level. Supplementary details are further considered at the following level, which is the process design level. Finally, on the right side, the sketch illustrates typical information considered at the equipment design level. It consists of sizing equipment via engineering design rules. In the conception of a process, the plant design and equipment design levels are the two extreme limits: the first one is mainly used for economic analysis while the latter concerns mainly front-end chemical engineering works. Usually process studies focusing on the development or optimization of new processes are limited to the conceptual design and process design levels.

Each proposed level can be associated to a step of the development of a process. The first step concerns the plant design. It allows determining a preliminary draft of the process, i.e., the necessary units and their sequence, e.g., conversion units, hydrotreatment, and reforming. This level is for the moment addressed in the industry by linear programming. A macroeconomic analysis can be performed at this step to determine the preliminary selling price, investment, and operating costs (Pham and El-Halwagi, 2012; Ponce-Ortega et al., 2012). A shortcut method for the synthesis and screening of integrated biorefineries was developed by Bao et al. (2011). Moreover, Morelos et al. (2015) developed a hybrid methodology for the synthesis of biofuel production processes based on a branch of available products and intermediates, the establishment of a superstructure with technologies and chemical species involved, mathematical optimization of production routes, and in-depth assessment of the most promising alternatives. The second step is the conceptual design step, which consists of specifying the conversion and separation operations and their sequence within the units (for example, extraction column, distillation column, and reactors) to establish a 

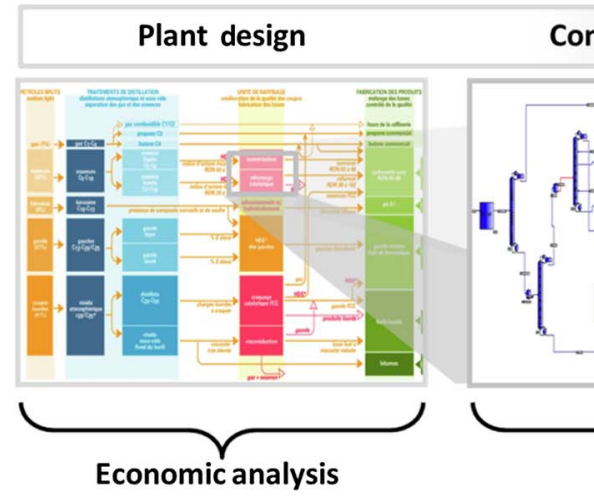

Conceptual design

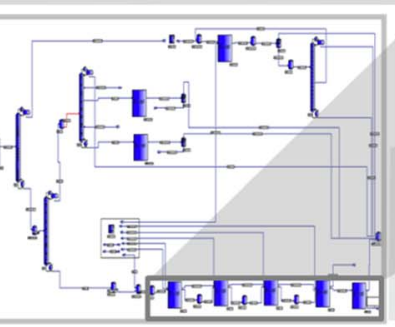

Heart of process engineering
Process design

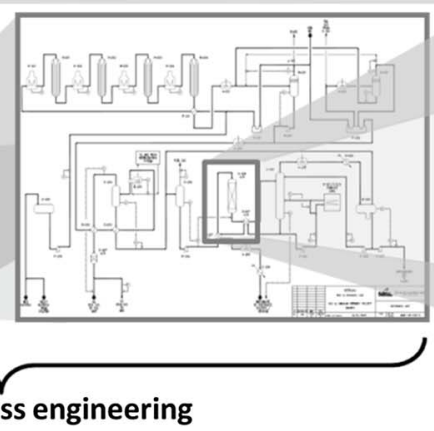

Equipment design

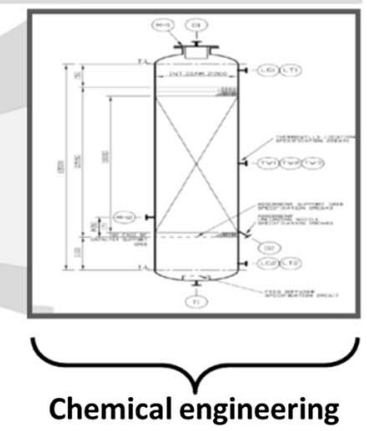

Fig. 1. Successive levels studied in process engineering.

mass balance of the process (Bertran et al., 2017a, b; d'Anterroches and Gani, 2005). This step also includes the determination of operating conditions (Bechara et al., 2016a, b; Tula et al., 2017). Once the material balance between conversion and separation units is established, additional devices are introduced during the process design step, such as heat exchangers or pressure-changing devices, e.g., compressors, pumps, and pipes (Chen et al., 2011a, b). At this stage, the optimization focuses on heat integration and its interaction with the rest of the process (OchoaEstopier et al., 2013). The purposes of the process design are to obtain the final and detailed flowsheet of the process, calculate precise heat and mass balances, and perform an economic evaluation of the process. Finally, the last step focuses on the sizing of each specific equipment (height, width, material, reactor technology, and associated internals). Note that the methodology is iterative. Even when simultaneous design methods are applied, because analysis of the results obtained at one-step may prompt re-evaluation or decisions.

The conceptual and process design may be connected to the cost estimate classification system developed by the Association for the Advancement of Cost Engineering (AACE International, 2005). The purpose of this classification is to estimate the maturity of a project. According to this system, conceptual design and process design correspond to class 4 and class 3 , respectively. Class 4 consists of determining the process flow diagram for main process systems, and class 3 involves establishing the preliminary piping and instrument diagram.

To clearly differentiate conceptual design and process design, a classification that distributes the decision variables between both steps is presented in Table 1 . The variables are divided into two groups: synthesis variables and design variables. The first group consists of binary variables describing the existence of specific operations while the second group is composed of operating conditions. As presented in Table 1, the objective of conceptual design is to determine the preliminary configuration of a process depending on yields and product qualities by focusing on the main operations, i.e., the conversion and separation operations. The main operating conditions are considered in the calculation only if they affect the configuration. A preliminary sizing of operations may be required to accurately determine the costs and energy consumption. The conceptual design allows evaluating the raw materials and characterizing the outlet flowrate. These values can be further used for a first estimation of the environmental impact from REACH EU regulation evaluation to Global Warming Potential (GWP) estimation. It is important to note that this first evaluation of GWP is overestimated because no energy integration is performed at this step. In process design, the environmental impact can be evaluated using a Life Cycle Analysis (LCA) methodology. It should be noted that the economic and environmental objectives are usually antagonistic. At this step, an automated development of chemical processes is required using a sophisticated algorithm for a multiobjective optimization because a single-objective optimization cannot identify the tradeoffs between conflicting performance criteria.

Many fields of expertise need to be considered during the process synthesis and design steps, and they could be organized into three main fields: physical science, process engineering, and applied mathematics. Figure 2 illustrates the interactions between those fields in a ternary diagram. On the left side, physical science is composed first of physics, which is the study of process streams and associated physical properties through space and time considering energy and force. Second is of chemistry, which is the study of raw or intermediate material transformation into desired products. Physics embodies the separation operations with required data such as thermodynamics, while chemistry represents the reaction operations with kinetic studies. On the right side, process engineering is divided into synthesis (combination of operations) and design (determination of operating conditions and sizing). Finally, the bottom part represents the applied mathematics required to solve the problem. It is split into the nonlinear system (where output is not proportional to change of input) and mixed system (presence of different types of variables such as integer and real). The two-colored triangles illustrate the mixes of the fields composing conceptual design and process design. Conceptual design, which is based on chemistry, involves many nonlinear variables and focuses mainly on synthesis that includes a few mixed variables. Process design is based on physics, involving few nonlinear variables and focusing mainly on designs that include a large number of mixed variables. 
Table 1. Variables and criteria in Conceptual Design (CD) and Process Design (PD).

\begin{tabular}{|c|c|c|c|c|c|c|c|c|c|c|}
\hline & \multicolumn{3}{|c|}{ Variables } & \multicolumn{7}{|c|}{ Criteria } \\
\hline & \multirow[t]{2}{*}{ Synthesis } & \multicolumn{2}{|c|}{ Design } & \multirow[t]{2}{*}{ Yield } & \multirow{2}{*}{$\begin{array}{l}\text { Product } \\
\text { quality }\end{array}$} & \multirow[t]{2}{*}{ Energy } & \multirow[t]{2}{*}{ OPEX } & \multirow[t]{2}{*}{ CAPEX } & \multirow[t]{2}{*}{ GWP } & \multirow[t]{2}{*}{$\mathrm{LCA}$} \\
\hline & & $\begin{array}{l}\text { Operating } \\
\text { conditions }\end{array}$ & Sizing & & & & & & & \\
\hline Conversion & $\mathrm{CD}$ & $\mathrm{CD}$ & $\mathrm{PD}$ & $\mathrm{CD}$ & $\mathrm{CD}$ & & & & $\mathrm{CD}$ & \\
\hline Separation & $\mathrm{CD}$ & $\mathrm{CD}$ & $\mathrm{PD}$ & $\mathrm{CD}$ & $\mathrm{CD}$ & & & & $\mathrm{CD}$ & \\
\hline Energy balances & $\mathrm{PD}$ & $\mathrm{PD}$ & $\mathrm{PD}$ & & & $\mathrm{PD}$ & $\mathrm{PD}$ & $\mathrm{PD}$ & & $\mathrm{PD}$ \\
\hline $\begin{array}{l}\text { Pressure } \\
\text { balances }\end{array}$ & $\mathrm{PD}$ & $\mathrm{PD}$ & $\mathrm{PD}$ & & & $\mathrm{PD}$ & $\mathrm{PD}$ & $\mathrm{PD}$ & & $\mathrm{PD}$ \\
\hline
\end{tabular}

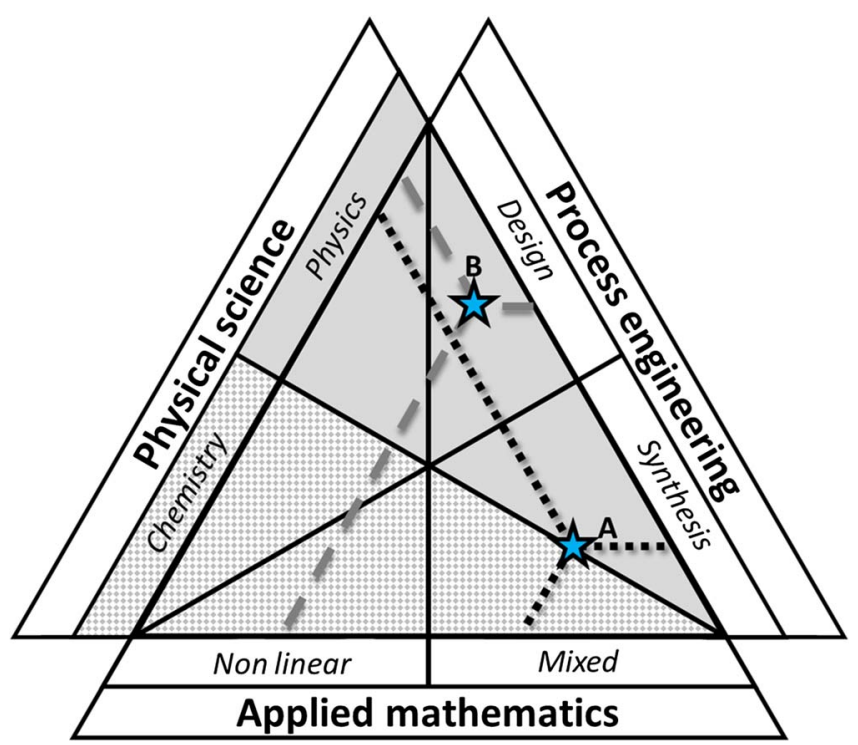

Fig. 2. Comparison between conceptual design (light gray) and process design (dark gray).

Process optimization has to be included in this work to create and develop an optimal process, i.e., the process achieving the best compromise between different criteria (yields, products quality, operating costs, investment, environmental impact, etc.).

To reinforce interest on the presentation used in Figure 2, we situate on such a diagram studies dealing with PSE. A study corresponding to point A would be characterized by large activities on mixed applied mathematics in the border between conceptual design and process design. There are many types of optimization problems: mixed integer programming, Mixed Integer Linear Programming (MILP), Mixed Integer Non Linear Programming (MINLP), mono-objective, multi-objective, etc. Many studies propose inventories of optimization methods and describe application cases in science and engineering (Benki, 2014; Poe and Mokhatab, 2016; Roy et al., 2008). Others review the optimization method used in a specific sector, for example, Asadi and Sadjadi (2017) for the green energy sector. Finally, some works focus on optimization methods applied on process synthesis (Chen and Grossmann, 2017;
Grossmann and Daichendt, 1996). The selection of the optimization method depends on the objectives, scale of the model, industry, strategy of resolution, etc.

Point B in Figure 2 would denote a study on process design using physics concepts to represent the problem. At the process design level, Cremaschi (2015) made an inventory of general optimal design methods but focused particularly on the separation system. Process integration, such as heat and water integration, is considered at this level. Heat exchanger network synthesis is a very broad theme based on the number of reviews (Grossmann, 1992; Gundersen and Naess, 1990; Morar and Agachi, 2010). Furman and Sahinidis (2002) proposed an annotated bibliography referencing more than 460 papers, computer programs, and commercial software dealing with heat exchanger network synthesis. Papers dealing with water network synthesis are increasing because of the growing interest in environmental impact and costs (Bagajewicz, 2000; Foo, 2009). Some works consider that heat exchanger network synthesis and water network synthesis affect each other; thus, they proposed a simultaneous synthesis of both networks (Ahmetović et al., 2015; Kermani et al., 2017). Finally, the state-of-the-art at equipment level is specific to each type of equipment. For example, Almeida-Rivera et al. (2004) and Segovia-Hernández et al. (2015) focused on the design of reactive distillation while Yildirim et al. (2011) worked on the design of dividing wall columns. Another example is the design of heat exchangers (Abou Elmaaty et al., 2017; Omidi et al., 2017).

Some reviews are general, such as the review by $\mathrm{Li}$ and Kraslawski (2004), which focused on the types of methods used for the optimal design of processes depending on the scale of study, or those by Chen and Grossmann (2017) and Westerberg (2004), which explained the developments and challenges in optimization-based process synthesis. It includes the developments of optimization methods, some conceptual and process design methods, and in-depth studies of specific processes such as heat exchanger networks, distillation networks, reactor networks, and water networks. To our knowledge, reviews at the conceptual design level are scarce and there is no general review that makes an inventory of methods and tools at that level. Note however the work of Grossmann and Daichendt (1996), which focused on specific mathematical approaches used at this level, and that of Yuan et al. (2013), which proposed 


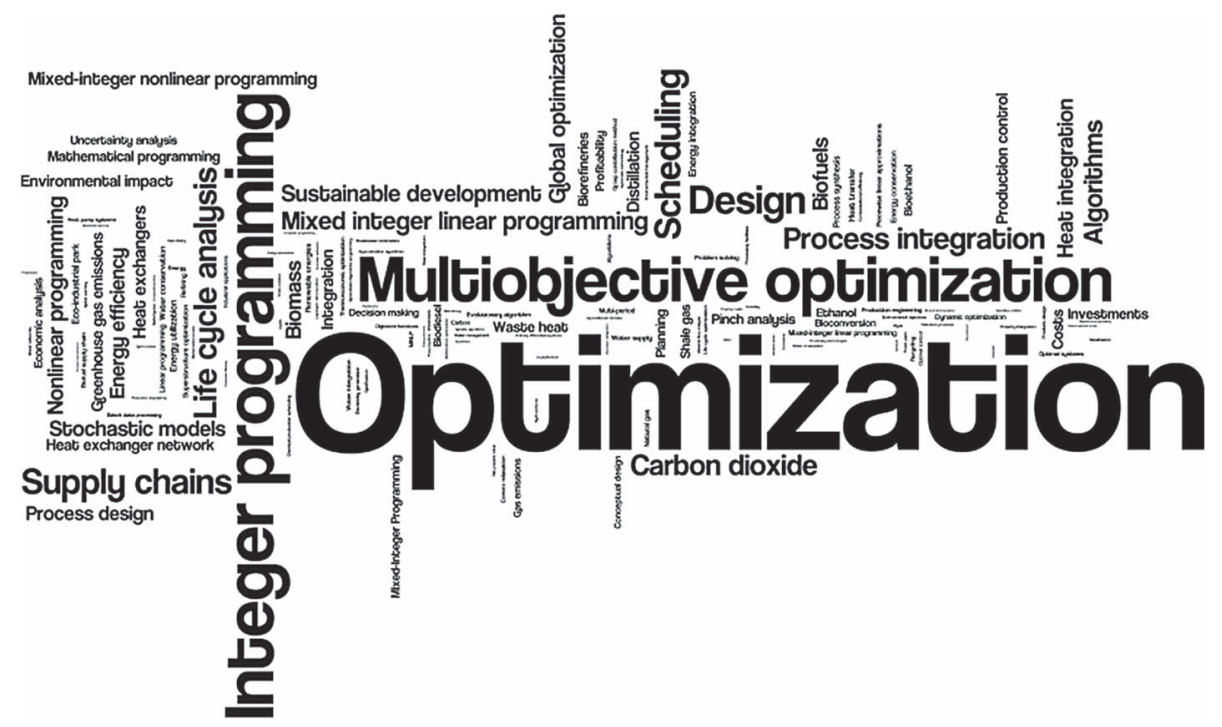

Fig. 3. "Wordle" of keywords in process synthesis research area (period 2011-2016).

a state-of-the-art review of methods and tools for the optimal design of biorefinery processes.

\subsection{Bibliometric analysis}

The objective of this section is to determine how key challenges and requirements for flowsheet synthesis and optimization have been addressed by the PSE scientific community in recent research. Therefore, a systematic literature review method composed of a search strategy and an analysis of the collected documents are performed. The purpose is to identify the main methods and approaches developed in the literature and to examine them thoroughly. It aims at identifying clusters of keywords and authors that correspond to the main thematic groups of the domain. The PSE research groups several topics or subjects: continue or batch, simulation or optimization, Linear Programming or Non Linear Programming with or without integer variables, mono- or multiobjective, etc. The main objective is to determine the relations between the methodology and the systemic problem approach.

The first step of our search strategy starts with the definition of relevant keywords, i.e., "process synthesis" and "conceptual design," in performing the search in scientific journals databases. With this research, a first list of papers was extracted. To complete this first list, we submitted queries to databases to retrieve papers referencing each of the first seed papers. Finally, more than 2500 articles published in different scientific journals were identified. In recent years, several reviews have been published on conceptual and process design, demonstrating the growing interest in the area (Barbosa-Povoa, 2017; Cremaschi, 2015; Westerberg, 2004). As a result, we focus our analysis on recent studies, i.e., list of articles published during the period between 2011 and 2016, and on research subarea not addressed by the previous recent reviewers. For example, the synthesis and design of batch processes, are mentioned but not further detailed in this paper due to the recent state of the art proposed by Pinto-Varela and Carvalho (2018).

After the application of the first steps of the method, in the remaining papers, the keywords specified in the corresponding section of the papers and in the title were extracted. The corresponding word cloud, which gives greater prominence to keywords that appear more frequently in the source papers, is illustrated with the wordle in Figure 3. This figure clearly highlights that the thematic subgroup "mono- or multi-objective optimization" is major with the economic dimension and environmental concerns, which are also frequently considered in recent papers. Moreover, in Figure 3, the topic around batch process, batch plant appeared with the keywords scheduling and supply chains. Energy is another major subgroup with research subjects dealing with pinch analysis, heat integration, heat efficiency, waste energy, and heat exchanger networks. As previously identified, distillation sequence also appears in the wordle, but it is less prominent than other themes related to process synthesis. Another comment is that the keyword reactor network synthesis does not appear. In fact, it is embedded in the research aspect related to biomass because in the period under examination, most of the research in this field is directed toward biomass conversion. The new applications of process synthesis are also visible, e.g., supply chain, biomass, and biofuels.

The major drawback of this wordle is the cumbersome number of keywords related to each research theme. To go further, a common approach to identifying the major thematic subgroups is to apply cluster analysis techniques. The available clustering methods can be classified into two categories: methods for which each element can only reside in a single leaf node in the tree and methods that are a consequence of a single cluster. In contrast to previous methods, in the second category, overlapping may occur and data elements can potentially belong to multiple clusters. Thus, we retain the latter type of methods. To summarize 


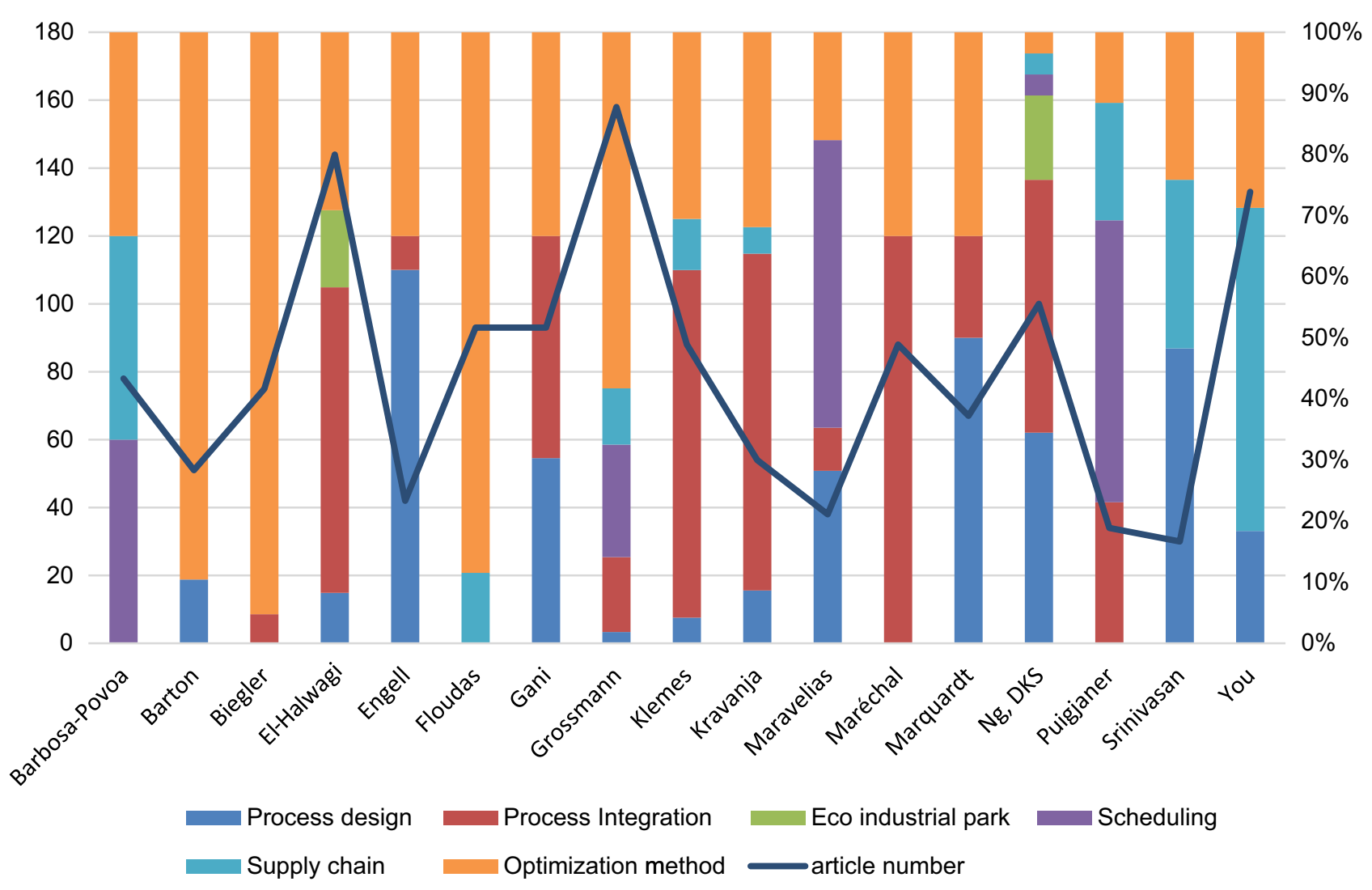

Fig. 4. Relationship between domain clusters and research teams.

the content of clusters, cluster labeling is automatically performed: terms that are more indicative receive a higher score leading to a ranking in the list of keywords belonging to the cluster under analysis. In addition to the cluster analysis, we also identify the most influential research teams and papers that played major roles. In the considered period, 1288 articles were published, and $95 \%$ of them were written by 17 research teams only (classified in alphabetical order):

- Prof. Barbosa-Povoa, Instituto Superior Tècnino Lisbon

- Prof. Barton, Massachusetts Institute of Technology

- Prof. Biegler, Carnegie Mellon University

- Prof. El-Halwagi, Texas A\&M University

- Prof. Engell, Technischen Universität Dortmund

- Prof. Floudas, Texas A\&M University

- Prof. Gani, Technical University of Denmark

- Prof. Grossmann, Carnegie Mellon University

- Prof. Klemes, Brno University of Technology

- Prof. Kravanja, University of Maribor

- Prof. Maravelias, University of Wisconsin

- Prof. Maréchal, EPFL

- Prof. Marquardt, RWTH Aachen University

- Prof. Ng, DKS Nottingham University Malaysia Campus

- Prof. Puigjaner, Universitat Politècnica de Catalunya
- Prof. Srinivasan, Indian Institute of Technology Gandhinagar

- Prof. You, Cornell University

Figure 4 depicts the coupling between the retained researchers' teams and the seven major clusters identified. Six of the seven clusters are directly related to the first keywords analysis illustrated in Figure 3. The only new cluster concerns eco-industrial park. In fact, this cluster arises from the keywords related to energy such as heat exchange, heat networks, and energy waste. Indeed, these keywords refer to both the process scale and an upper scale with the exchange network between different entities, i.e., eco-industrial parks, which could be associated to the plant design level as discussed in section.

While these teams are all working on process and conceptual design, from this figure, one can identify a first category of authors who are more focused on optimization methods, i.e., Barton, Biegler, Floudas, and Grossmann. For these groups, process synthesis is one application of the optimization methods that they develop in their research teams because the conversion of process alternatives into mathematical models often results in MINLPs that are difficult to solve.

For other authors, mono- or multi-objective optimization is often a tool that is included in their methodology. One major observation from this figure is that the authors 


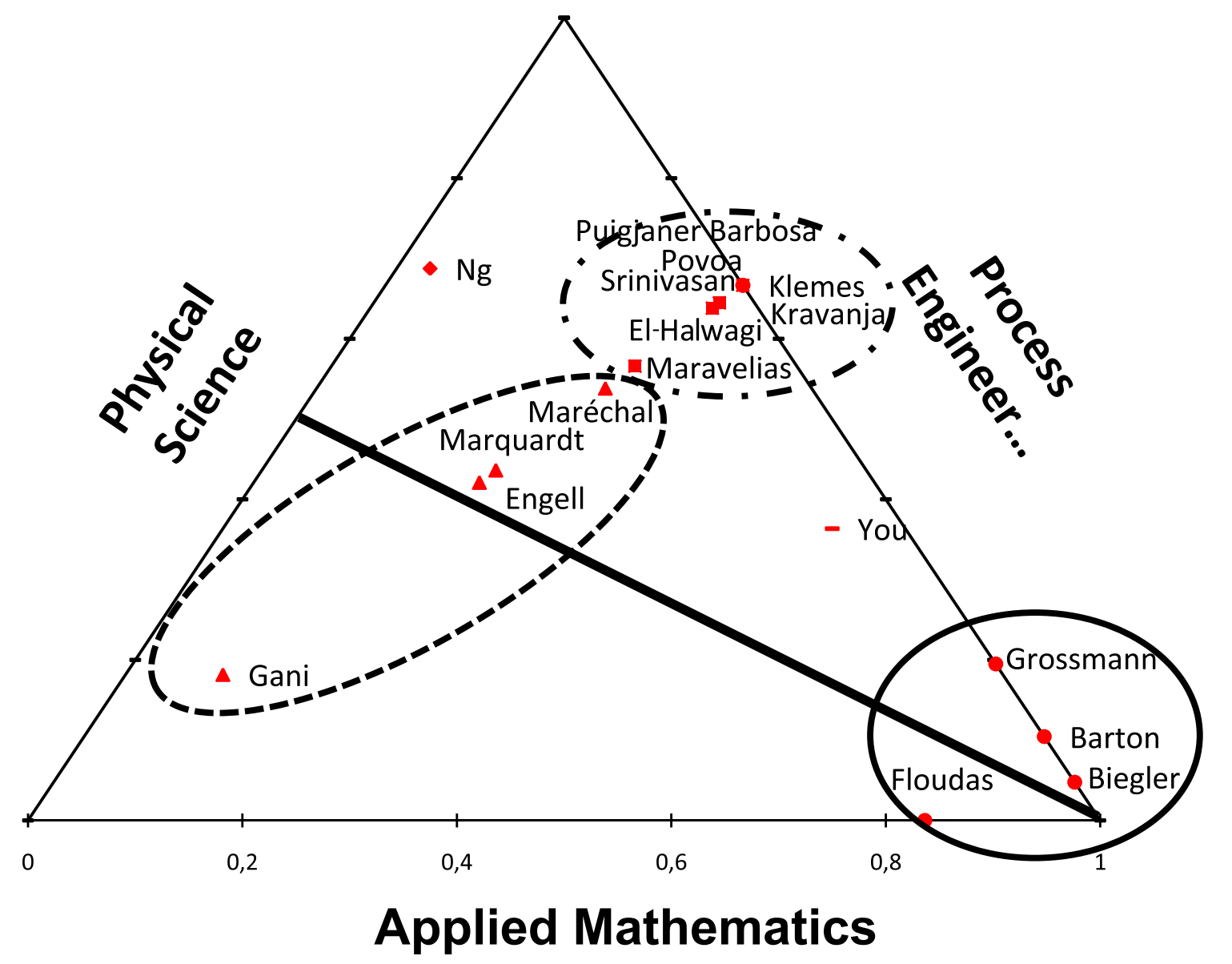

Fig. 5. Ternary diagram presentation on Process System Eng. domain.

study the process synthesis under the domain of their scientific backgrounds. Indeed, You, Puigjaner, and Srinivasan are more focused on supply chain; Klemes, Kravanja, El-Halwagi, and Maréchal on heat integration aspects, whereas Maravelias tackles the problem with his vision as a scheduling specialist. The synthesis design, planning and scheduling of batch and semi continuous plants were still ape due to new market environment that favors high values low volume products an important research domain in PSE. Due to its inherent flexibility, batch plants can be easily reconfigured or adapted to permit production adaptation to cover a wide range of operating conditions within the same plant configured. In some cases, batch or semi continuous processes present also economical and technical advantages.

The design of batch processes was reviewed by Reklaitis (1989), who defined the conceptual batch design process using problem as decomposed into four decisions levels: determination of the processing network, selection of the best operating strategy, allocation of equipment items to tasks and storage, and sizing the pieces of equipment. More recently, Barbosa-Povoa (2017) proposed a critical review of the design of batch plant where both the grassroots and the retrofit design were analyzed. The multiproduct and the multipurpose plants were considered. While a number of breakthrough, she identified several research streamlines for further developments: design with detailed structural and operational aspects, incorporation of detailed financial elements at the design level, multiobjective design with environmental aspects, models improvement as well as solution methods, taking account uncertainties, etc. In their recent study (Pinto-Varela and Carvalho, 2018) underpin the importance of batch process design reviewing the methodology used in this research area with this review, authors also propose a pioneer generic framework for sustainable batch process design.

A majority of authors are more on the process design area except for two of them who are more focused on conceptual design, i.e., Gani and Engell. Finally, another category of researchers, composed of Marquardt and $\mathrm{Ng}$, try to have a more comprehensive approach that seeks to integrate all previous elements. To analyze the different approaches developed by the previous authors in more detail, the ternary diagram in Figure 2 is used to position them relative to each other as illustrated in Figure 5.

The diagram in Figure 5 shows what could be considered as an approximate position of the research teams identified. It is important to note that different works are located around a point representing each group activity and should be considered as a gravity point only, the scope of work of each team being more of a zone than a single point. To determine the different zones for each researcher, 
Table 2. Top 10 keywords published by Gani, Engell, Marquardt and Maréchal.

\begin{tabular}{|c|c|c|c|c|c|c|c|}
\hline Gani & Rep. & Marquardt & Rep. & Engell & Rep. & Maréchal & Rep. \\
\hline Design & 11 & Optimization & 23 & Optimization & 12 & $\begin{array}{l}\text { Multiobjective } \\
\text { optimization }\end{array}$ & 57 \\
\hline Product design & 10 & Conceptual design & 12 & $\begin{array}{l}\text { Evolutionary } \\
\text { algorithms }\end{array}$ & 7 & Optimization & 28 \\
\hline Optimization & 8 & Distillation & 12 & Scheduling & 6 & Carbon dioxide & 25 \\
\hline Process synthesis & 8 & Design & 9 & Uncertainty analysis & 6 & Energy efficiency & 23 \\
\hline Crystallization & 7 & Process design & 9 & Chemical process & 5 & Process integration & 21 \\
\hline Group contributions & 7 & Biofuels & 7 & Uncertainty analysis & 5 & Process design & 20 \\
\hline Liquids & 7 & Algo & 6 & tual design & 4 & Waste heat & 12 \\
\hline Phase equilibria & 7 & Distillation columns & 6 & Controllers & 4 & Design & 12 \\
\hline Solubility & 7 & Parameter estimation & 6 & Emulsion polymerization & 4 & Biomass & 11 \\
\hline Systematic methodology & 7 & $\begin{array}{l}\text { Model predictive } \\
\text { control }\end{array}$ & 5 & Integer programming & 4 & Pinch analysis & 9 \\
\hline
\end{tabular}

one approach could be by using a statistical study to know the interaction between the three domains; however, this is not performed here.

Mainly, three research groups can be identified. The first group called the mathematical approach group is focused on mathematical methods and comprises the research works of Grossmann, Floudas, Barton, and Biegler. The second group called the process integration group can be identified around the activities of Kravanja, El-Halwagi, Maravelias, Puigjaner Srinivasan, and Klemes. Finally, the last group called the Multi Physics Multi Purpose (MP2) group could be composed of the works Maréchal, Marquardt, and Engell including the activities of Gani's team. With regard to the work by You, its intermediate positioning is due to his numerous activities on the supply chain. Ng takes a typical place due to a few number of keywords in the mathematics domain.

To qualify the mathematical approach group, the top 10 keywords (published during the period from 2011 to 2016) are as follows: optimization with 124 repetitions, integer programming (69), protein (51), global optimization (47), nonlinear programming (46), algorithms (43), process control (27), natural gas (26), amino acid sequence (25), supply chain management (24), and scheduling (21). A strong activity on applied mathematics can be highlighted with some applications at different scales.

For the process integration group, the main keywords are optimization (161), heat exchanger network (109), multiobjective optimization (51), mathematical programming (40), biomass (36), integer programming (36), supply chain (35), environmental objectives (28), integration (28), design (24), decision making (23), biorefineries (22), and eco-industrial park (22). Those keywords represent various levels of scale with a very physical approach both in the concepts and in the areas of applications; keywords such as supply chain or eco-industrial park appear. This second group is more process design-oriented, such as the work of Maravelias (Wu et al., 2016), which offers an effective representation of the superstructure based on scheduling concepts. Moreover, regarding Figure 4, this group is characterized by a few papers published for conceptual design. These activities are more focused on supply chain, scheduling, and eco-industrial parks. For these two groups, many reviews have been written particularly the recent works of Cremaschi (2015) and Chen and Grossmann (2017). Some literature reviews are dedicated to the mathematical approach group and process integration group (Chen and Grossmann, 2017; Cremaschi, 2015); therefore, we consider to study the objectives and the methodology developed by the MP2 group.

To focus on this last group composed of Gani, Engell, Marquardt, and Maréchal, the top 10 keywords reported in their respective works published between 2011 and 2016 are synthetized in Table 2.

These authors deal with both conceptual design and process design problems with several levels of mathematics and different applications. Therefore, it is appropriate to summarize these activities to assess the complementarity between various approaches to be able to solve future challenges. From the analysis of the keywords of this table, it can be observed that all fields between the conceptual design and process design are studied.

Moreover, this keyword list provides more details on the activity of each author to represent the bubble around the gravity points reported in Figure 5. Gani's activity is more focused on conceptual design. In contrast, Maréchal is more focused on optimization, particularly on multiobjective optimization to increase energy efficiency. Marquardt's activities deal with both conceptual design and process design, with a part on the control applied to distillation columns. Engell's activities mostly correspond to the middle of the group using different optimization methods such as stochastic methods.

To understand and imagine some methodologies for answering the challenges of the future, we propose to organize the present review by authors' activities within the MP2 group. First, Gani's activities in conceptual design are summarized; second, Engell's work on optimization is 
presented. Process design is then outlined by Maréchal's activities. Finally, Marquardt's activity, which is characterized by a wide spectrum of studies, will conclude the next section to take into consideration both conceptual design and process design.

\section{Review}

\subsection{Conceptual design from molecular scale to process scale}

With the idea of integrating process controllability, environmental impact, and energy requirements in the early stages of process design, Gani et al. (1997) developed the so-called Integrated Computer-Aided System (ICAS). Its aim is to assist and speed up the synthesis of processes. This platform is composed of computer-aided tools for modeling, simulation, property prediction, synthesis, design, control, and analysis of systems. ICAS is an equation-oriented process simulation framework with various toolboxes organized in such a way that it is a fully integrated computer environment. Such a platform is very effective because the loss of information between toolboxes is limited. ICAS is composed of four main sections, namely model generator, problem definition, toolboxes, and simulator (Gani et al., 1997), as illustrated in Appendix A.

The model generation involves describing the representation of a process (name, conservation principles, constraints, boundary values, etc.) through equations. Various forms of models can be generated depending on the needs of a specific design problem. All the information required by the simulator such as flowsheet, thermodynamic background, reaction kinetics, control strategy, simulation mode, numerical solution method, and initialization strategy are described in the problem definition section. The simulator is divided into four subsections. First, the equation subsection contains the model library unit operation models and properties prediction. Second, the adaptation subsection includes rigorous model reduction and simplification if required. This subsection is essential if the model has to be simplified, for example, for control studies. The third subsection is the analysis, which evaluates the set of equations to determine the additional information required for the resolution. The last subsection, i.e., the solver subsection, allows solving the problem depending on its type (MILP, MINLP, linear programming, etc.). Finally, the toolboxes are specific computational tools that interact with each other. In practice, the user chooses active toolboxes as a function of the problem to be solved (Fedorova, 2015). Over time, ICAS has been continuously improved by creating more than 20 toolboxes for a large portfolio of situations.

Because of the drawbacks of heuristic-based approaches mentioned in the introduction and the limitation of mathematical programming to moderate-size MINLP problems (due to integer variables and nonlinear equations), Tula et al. (2015) proposed a hybrid approach. Indeed, physical insights from knowledge-based methods are used to narrow the search space of alternatives; then, smaller size mathematical problems are solved. A process synthesis approach is developed through a process group contribution method. Process flowsheet alternatives are generated in a similar manner to the combination of atoms or groups of atoms to form molecules in computer aided molecular design. This method considers a function of structurally dependent parameters for each property of a compound, and the parameters are determined based on the frequency of the group occurring in the molecules (Gani et al., 1991). In the case of a process group approach, a group represents a unit operation or a set of unit operations and the property is the performance of the operations in the flowsheet (d'Anterroches and Gani, 2005). First, process alternatives are generated by the use of building blocks, i.e., a functional process group, representing process operations. The flowsheet connectivity rules to join building blocks allow generating feasible alternatives. The most promising alternatives according to performance criteria are selected for further analysis through mathematical models to reach an optimal solution. The proposed methodology, as shown in Appendix B, is composed of seven main steps. Each step relies on methods and toolboxes necessary for calculations (most of them were developed in the ICAS framework). The methodology starts with the definition of the synthesis problem: inputs, outputs, and reaction data. It ends with a process selection based on a multicriteria analysis (economic, environmental, process safety, and energy efficiency). Once the process is selected, a rigorous simulation is performed to verify its feasibility and calculate accurate results.

As claimed by the author, the main advantage of this framework is the systematic approach for process synthesis, which also facilitates the proposition of innovative solutions. Its main difference compared to the conventional approach is that it is neither iterative nor based solely on mathematical optimization. However, as a result, it does not guarantee a rigorous optimality. Moreover, this approach inherits the major drawback of contribution methods, i.e., its strongly combinatorial problems due to enumeration techniques. Indeed, the connectivity rules are heuristics, which do not prejudge the feasibility but looks at whether a connection between a functional block is coherent with the purpose of the process. In this step, the goal is more of generating alternatives rather than discriminating them. Moreover, the last steps of the methodology are built to carry out this selection process. As a result, the application cases presented in the literature are basic. The presented method has, for instance, been applied to the production of benzene from toluene and hydrogen, and more specifically on the separation section (Tula et al., 2015). In that specific case, the authors found 47 different process groups that induced 74046 potential combinations. However, many combinations were structurally infeasible, and the superstructure was reduced to 272 feasible combinations. Nevertheless, this quantity is extremely large for a precise study; thus, a reduction algorithm was applied to reduce the superstructure further. Finally, only 32 alternatives finally remained. The reduction algorithm was based on logical rules and knowledge of experts. In other examples, d'Anterroches and Gani (2005) focused only on 
the separation of five components and Babi et al. (2015), Tula et al. (2015), and Tula et al. (2017) considered processes composed of one reaction block and purification blocks (limited to between two and four unit operations).

The process group contribution method and the ICAS methodology are further integrated into a larger simulation tool to perform process synthesis intensification as well (to include the recent breakthroughs in process intensification in the set of possible process alternatives) (Tula et al., 2017). The framework consists of three stages:

- Stage 1 - Process synthesis: definition of the problem, objective, constraints, and performance criteria.

- Stage 2 - Design and analysis: a base case with conventional unit operations satisfying process constraints is established and analyzed using a rigorous simulation and the specified performance criteria. The goal is to identify process bottlenecks on sustainability and to translate them into new design targets for the generation of more intensified alternatives.

- Stage 3 - Innovation design: process integration is performed at different scales.

In conclusion, ICAS and ProCAFD are able to propose automatically a large number of alternatives and to filter them with respect to feasibility and performance criteria. The alternatives can be industrially well-known solutions or innovative solutions. The main advantage of this hybrid method is that it allows enumerating and analyzing a vast set of alternatives. However, the determination of the optimal process is performed with a succession of selections performed by the user based both on the results obtained and on knowledge in process engineering. While the final process may respect the criteria of selection, it may not guarantee to obtain the optimal process among all alternatives generated. Moreover, as enumeration is a process based on human knowledge, some promising process structures remain undisclosed. Indeed, the connectivity rules and the rules used for innovation design, i.e., stage 3, are not precise and exhaustive enough to generate all process alternatives. On the other side, to eliminate this drawback, an increase numbers of rules (to be more precise and exhaustive) is required but it would lead to an ineffective tool for process design because it is impossible to manage and maintain all these rules (often contradictory) in PSE.

\subsection{Optimization at process level}

In practice, to deal with the chemical process synthesis issue, a global optimization-based approach that comprises the mathematical models of the superstructure, unit operations, constraints, and objectives would be the ideal approach. Unfortunately, as previously discussed, the resulting optimization model cannot currently be solved systematically in reasonable computation time, especially if it gathers a fine and detailed modeling of the phenomena that occur in each unit operation. In that case, even convergence to a local optimum may not be achieved. Furthermore, an increase in the number of alternatives that seems promising and which should be considered leads to an exponential increase in the size of the solution domain (because of the discrete variables). To overcome these problems, different approaches have been proposed in the literature. Besides the hybrid method presented in the previous section, some mathematical approaches reduce the complexity of the optimization model by reducing the number of design variables or alternatives, proposing new modeling, applying iterative procedures, or including decomposition techniques as detailed by Urselmann and Engell (2015). However, these approaches exhibit some drawbacks: exclusion of the globally optimal solution for the approach based on the reduction of the complexity and convergence to local optima (for large-scale problems) of the MINLP, which depends on initialization. In addition to the previous drawbacks, achieving the required accurate and relevant model is a time-consuming task, which requires tremendous modeling effort for the formulation of equations for (1) the mathematical model of all design alternatives, (2) process constraints, and (3) process models.

To overcome some previous weaknesses and intensify and shorten the process synthesis task, Urselmann and Engell (2015) introduced a Memetic Algorithm (MA). MAs are population-based evolutionary algorithms, which are combined with local optimization strategies. Their approach separates the degrees of freedoms, i.e., the design variables that define the discrete and continuous structural design decisions from the determination of the corresponding state variables. Therefore, the MA couples an evolutionary strategy that performs a search in the space of discrete and design decision with local optimization (derivative-free optimization method in their tool) of the continuous parameters to improve the design proposed by the previous step. In this method, each individual is a process alternative. First, the individuals are evaluated, and the discrete variables for the selection of the possible elements in the superstructure and the continuous design variables are chosen. The search space must contain all the relevant and feasible process alternatives including the global optimal solution. Once the superstructure is set, the determination of the corresponding state variables is performed through an optimization using a mathematical programming method, i.e., by solving a nonlinear and constrained continuous problem. The state variables are determined by rigorous and realistic models for superstructure elements, e.g., unit operations.

In a recent development (Janus et al., 2017; Urselmann et al., 2016), at each iteration of the derivative-free optimization method, the MA uses process simulation software to simulate the design alternatives. The process model is defined by discrete variables, i.e., definition of the model elements and their connections in the MA. However, as they are evaluated after simulation, the objective function(s) and constraints that gather state variables become implicit. As a result, constraints are handled by the MA at different levels: constraints on the design variables are treated by the evolutionary strategy while model equations are checked after simulation. There is no global treatment of all constraints. Furthermore, the design alternative under study is evaluated only if the simulation converges. This methodology has been used to solve the superstructure of a reactive 
distillation column with an optional external reactor (Urselmann and Engell, 2015). To represent all suitable design alternatives, the superstructure comprises the following:

- an optional external reactor, which can have a volume of zero, to represent design alternatives without CSTR;

- a maximal number of stages, of column, which can be deactivated to represent columns with a smaller number of stages;

- all possible feed streams for all raw materials and all possible exchange streams between the reactor and the stages of column in both directions, which can be zero if the stream does not exist in the actual design under study; and

- the amount of catalyst on each stage of column, which can be zero, to represent stages with a purely separating functionality.

They succeeded in proposing different alternatives in process flow scheme while maintaining the same profitability chosen as objective function.

Another approach proposed by Corbetta et al. (2016) couples an optimization method with commercial software of flowsheeting. In their work, a new interface between the commercial process simulator PRO/II and the optimization environment of GAMS for the structural and parameter optimization of this type of flowsheet with rigorous and detailed models is proposed. The optimization problem is formulated within the generalized disjunctive programming framework and the solution of the reformulated MINLP problem is approached using a decomposition strategy based on the outer-approximation algorithm, where Non Linear Programming (NLP) subproblems are solved using the derivative-free optimizer belonging to the BzzMath library, and MILP master problems are solved using CPLEX/GAMS (the corresponding block flow diagram methodology is shown in Appendix C. Several validation examples are discussed from an economic optimization of two different distillation columns to a distillation sequencing with simultaneous mixed-integer design of each distillation column for a quaternary mixture in the presence of azeotropes. This study opens some large perspectives in the optimization process level. The purpose of a recent study is to provide a superstructure MINLP optimization within the commercial simulator ProSimPlus. The entire optimization loop is directly managed by the simulator and both continuous variables and discrete integer variables are optimized simultaneously by an external metaheuristic optimizer called Mixed Integer Distributed Ant Colony Optimization (Zhao et al., 2018)

\subsection{Process integration}

Energy is the keystone of the optimisation multi-objectifs de systèmes energétiques intégrés (OSMOSE) platform. It is a platform of flowsheeting, process integration, and costing tools for the study and design of complex integrated energy systems (Maronese et al., 2015; Palazzi et al., 2010).
This platform combines thermodynamic computations, power and energy integration, and economic and environmental aspects. OSMOSE includes a set of analysis tools such as Pareto curve analysis, sensitivity analysis, monoand multi-objective optimization (Maronese, 2014). The optimization method of OSMOSE is a multiobjective evolutionary algorithm (Bechara et al., 2016b, c; Bolliger et al., 2005).

According to Maronese (2014) and Maronese et al. (2015), OSMOSE has three main uses:

- post-analysis (for example, pinch analysis) of models created with other types of software;

- simultaneous analysis of models developed with other types of software such as optimization and sensitivity analysis. This mode includes the conception of energy system superstructures;

- division of complex energy systems into several units and the possibility of performing analysis on them.

The platform is divided into different modules to separate the models (unit operations, processes, etc.) from analysis with the calculation of indicators (Bolliger, 2010). This technique allows reducing calculations, structuring the calculations easily, and simplifying connections with external software. Appendix D illustrates the structure of OSMOSE. Appendix E illustrates an example of a methodology using OSMOSE to synthesize a superstructure and determine the optimal process (Bolliger, 2010). Three main steps are considered. First, after defining the objectives of the study, the model is developed. This involves identifying the unit operations, pathways, processes, or modules to generate the superstructure and to realize a pre-analysis in order to find the best indicators for the optimization. During the second step, the objective functions, the variables and the constraints of the optimization model are defined and the model is solved. The results are finally evaluated with indicators, which makes possible the identification of an optimal process that can then be considered for further process design studies.

It is well known that energy systems and particularly systems dealing with renewable energies depend a lot on

- time dependent factors, i.e., composition and nature of raw materials; and

- time variant factors, i.e., energy requirements.

Thus, multiperiod aspects have also been included in OSMOSE and this contributes to the originality of the tool. The periods can be fixed by the user (Fazlollahi and Maréchal, 2013) or determined through a method that minimizes the number of periods and maximizes their quality simultaneously (Fazlollahi et al., 2014a, b, 2015). Celebi et al. (2017) worked on the optimal design of second-generation biorefineries using wood as raw material for producing high-value intermediates as much as possible. They considered several potential products, among them hydrous ethanol, anhydrous ethanol, vanillin, formic acid, etc. The superstructure comprises combinations of black boxes that constitute the production processes of these products. The 
linear regressions for the black boxes are fitting using rigorous simulations of each process. The purpose of the optimization is to determine the best utilization of the raw material, which can also be considered as the best distribution of raw material between different processes. A total of 150 alternatives with different product distributions have been evaluated. The multiobjective optimization was based on two criteria: minimization of total costs and minimization of environmental impact. The alternatives were ranked according to the criteria, and only the 34 most promising scenarios were selected for further evaluation.

\subsection{Ontology}

Knowledge on process design methods and design rules constitutes one of the most valuable assets of an engineering company. This knowledge is mostly known implicitly by technical experts, relying on the personal experience and background of each designer. In the same, due to data and knowledge explosion, old practices in modeling knowledge and using them for decision making become inadequate, as they are suboptimal. As process engineering experiments, computational models, and conventional experimentation continue to generate a large amount of diverse data, engineers require methods and tools for storing, managing, sharing, and reusing these data effectively (Venkatasubramanian, 2009). Therefore, we need new ways of knowledge modeling and management, which require an open, scalable, and flexible approach to knowledge modeling. Artificial intelligence could offer new opportunities to realize this task with two main categories of approaches: symbolic with the modeling and manipulation knowledge through symbols, and numeric with the use of algorithms for automatic learning from data. To this end, ontologies for the symbolic approach and deep learning for the numeric approach are expected to play a crucial part in the future of PSE. The former is a particular technique of machine learning. Conventional machine learning techniques are limited in their ability to process data in their raw form. They require a data pretreatment step that can introduce some bias in the learning step. Deep learning methods allow computational models that are composed of multiple processing layers (in a neural network) to learn some features of raw data with multiple levels of abstraction (Le Cun et al., 2015). Currently, to determine all the parameters of a neural network, the learning step of these algorithms requires a large amount of data (several millions to achieve results equivalent to those of a domain expert). Data availability is the most important drawback of deep algorithms, which limits their range of applicability; this is particularly true for process simulation for which generic data are relatively limited. Deep learning will have more success in the future because of research advances in the mathematical community to improve learning algorithms, network architectures, and reduce computational time. The recent overview on the recent progress on machine learning (and more specifically on deep learning) proposed by Lee et al. (2018), discusses also the implications of these advances for a wide variety of application in the fields of process and energy systems engineering. Currently, ontology is more operational than the symbolic approach and more particular than deep learning. The goal of this section is to present this new challenging domain.

The widely accepted definition of ontology is "a formal, explicit specification of a shared conceptualization" (Gruber, 1993). To go deeper, Zhou et al. (2017) explained that conceptualization refers to an abstract model of some phenomenon, explicit means that the concepts used and the constraints on their use are clearly defined, formal is required because the ontology must be machine readable, and shared introduces the notion that the ontology gathers consensual knowledge, i.e., accepted by the community.

First, ontology can be defined as a set of graphical databases that are used to store information semantically. In this graph, nodes represent individuals, and edges represent the connections between nodes, including relations such as "isPartof" or "isConnectedTo." A collection of nodes can define the class, and a collection of edges represents properties. Therefore, ontology denotes a conceptual data scheme that represents the relevant domain entities and their relationships by means of classes and relations. Ontologies are flexible data structures that can be changed and adapted at run time. They also allow representing the semantics of design knowledge in a formal way that a computer can interpret. These characteristics enable the provisioning of advanced computer science methods for managing, enriching, and searching knowledge (Brandt et al., 2008). In their study, Morbach et al. (2009) describe in more detail "what is" and "what is not" an ontology.

In the domain of chemical and process engineering, the number of available ontologies is increasing and demonstrating the growing interest of the community. Among them, one can mention the following to facilitate the identification of the best option for the optimization problem:

- process supervision of large scale chemical plants (Natarajan et al., 2012);

- computer-aided process engineering (Morbach et al., 2007, 2009);

- batch process (Muñoz et al., 2010);

- process integration and interoperability (Muñoz et al., 2013);

- process simulation and optimization in the context of eco-industrial parks (Zhou et al., 2017);

- pharmaceutical product development and manufacturing (Hailemariam and Venkatasubramanian, 2010; Venkatasubramanian et al., 2006);

- petrochemical processes (Ni et al., 2011), and

- biomass and biorefineries (Trokanas et al., 2016).

Indeed, ontologies are closely related to mathematical sets, and this link can be exploited during decision making in a stochastic search or in deterministic optimization problems. In their study, deterministic optimization represents the formal part of the decision making, while ontology represents the informal one (Zhou et al., 2017). The linkage between the formal and informal parts allows the identification of the most acceptable solution during the optimization step. 
Table 3. Critical analysis.

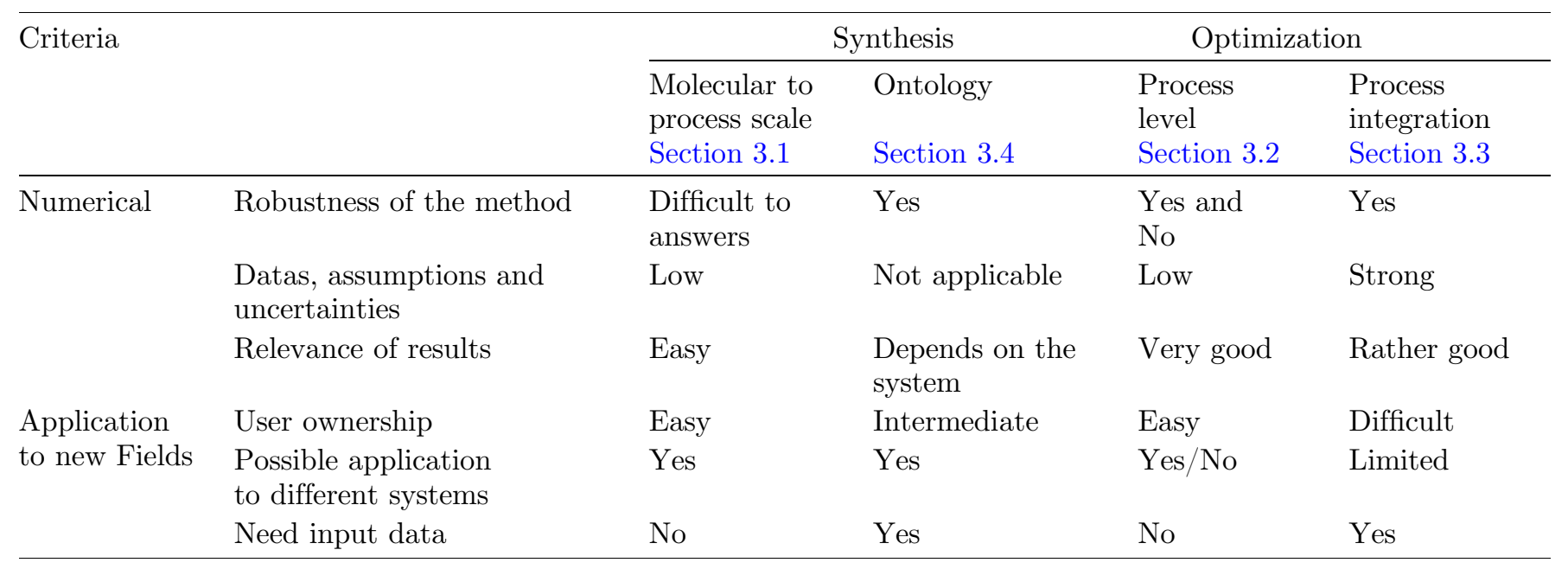

Among the reported ontologies for chemical process engineering, OntoCAPE (Morbach et al., 2009) is the most widely accepted tool. It is an ontology created for computeraided process engineering, which explicitly specifies a conceptualization of the process engineering domain, containing concepts of chemical processes and materials, strategies for numerical solution, mathematical models, and concepts related to modeling and design. It covers major engineering activities including the design and operation of chemical processes. Appendix $\mathrm{F}$ shows an overview of the OntoCAPE structure. It is organized using three structural elements: layers, modules, and partial models. Layers subdivide the ontology into different levels of abstraction with the top layers being general and applicable to multiple domains, while the other layers are specific to process engineering applications. OntoCAPE is divided into meta, upper, conceptual, application-oriented, and applicationspecific layers as summarized in the rest of this section.

The meta layer contains fundamental modeling concepts and provides the ontology design guidelines. This layer introduces the concepts of hierarchy (mereology) and connectivity (topology), such as the aforementioned relations "isPartOf" and "isConnectedTo." The upper layer defines concepts from general systems theory with the module system. OntoCAPE gathers different aspects of a chemical process system: requirements, function, realization, behavior, and performance. These decompose a complex chemical process, into manageable parts. The conceptual layer gathers a description. The PSE domain is described by four models, namely chemical process system, mathematical model, material, and supporting concepts. The latter provides fundamental concepts such as space, time, and physical dimensions. The material module is for the description of materials and their properties. The mathematical model represents all the concepts required for describing and creating mathematical models. The chemical process system represents all the concepts that are directly related to chemical plant operations. It is further divided into submodels to represent (1) the purpose of a chemical process through the description of the physical, chemical, or biological procedures, and (2) the process automation. The application-oriented layer allows to detail further the process, for example, the process unit partial model enables the description of typical unit operations such as the mixing unit, heat transfer unit, and distillation system. The plant equipment and process control equipment are partial models of the Chemical Process System realization from the conceptual layer. The bottom layer, which is the application-specific layer, provides classes and relations for practical applications. Kokossis et al. (2016) presented an approach to model, acquire, and beneficially reuse knowledge in process synthesis. They propose a method that combines optimization with ontological knowledge modeling in order (i) to easily interpret optimization solutions, (ii) to learn during the progress of optimization and to guide the search toward the optimum solution within predefined and on-the-fly created constraints, and (iii) to simplify solutions dynamically and in agreement with the problem formulation to accelerate the search (Kokossis et al., 2016). The main idea of their approach is that optimization (based on explicit knowledge) is the best way to generate solutions while tacit knowledge is the best way to select solutions. The knowledge, which is modeled with ontology, is used to visualize design themes, guide the optimization search, and dynamically adjust the superstructures. Ontology allows systematizing solution features by their performance and contribution.

In their method to manage the complexity involved in the redesign of chemical processes, López-Arévalo et al. (2007) included ontology to generate automatically alternative representations of an existing process at several levels of abstraction, i.e., hierarchical sets of units and meta units organized according to their functions inside the process. The ontology is contained in a case-based reasoning system to enable the retrieval and adaptation, from a library of cases, of similar units or meta units. As an output, the case-based reasoning system proposes a set of process alternatives while keeping the same functionality, e.g., a reactive distillation column can replace a reactor and separation units. Thus, the abstraction, owing to the ontology, can 
- reduce the complexity of the representation of a practical process by reducing the number of features, relations, constraints, etc.;

- increase the flexibility of reuse, because abstract solutions can be suitable for a large spectrum of practical concrete problems. The higher the level of abstraction of the reused solution, the more the newly refined solution may differ from the solution contained in the original case. This allows to not only increase the number of process alternatives but also to propose.

\section{Analyses and perspectives}

In the present article, several approaches for process synthesis are described to present a quick overview of different strategies mostly used in the literature. These different approaches naturally present advantages and disadvantages.

To illustrate, the methodology presented by Urselmann et al. (2016) and Corbetta et al. (2016) can solve a problem very quickly in terms of "preparation." In contrast, for example, the ProCAFD toolbox does not consider the energy integration during the synthesis of a superstructure, and therefore, a supplementary study is required to design the heat exchanger network of the optimal process and optimize the consumption of utilities. This is a key step because the energy efficiency strongly depends on the energy integration. The energy indicators used during the selection of the optimal process may not be meaningful.

According to the studies performed using OSMOSE, this software has been used for many purposes from the optimization of operating conditions to the optimization of raw material allocation. However, this tool does not provide innovative aspects in process conception. Consequently, it is appropriate to determine and optimize a process from a known superstructure. Typically, OSMOSE includes the energy integration via pinch analysis as a criterion for optimization. The other advantage of OSMOSE compared to other tools is the parallelization of calculations, which reduces the resolution time as much as possible, and the possibility to address seasonality.

Ontologies are a tool for knowledge representation, sharing, and reuse. Thus, the number of available ontologies is increasing, but the concomitant reuse activities do not follow correspondingly. This is particularly true in the domain of PSE, where the ontology development has been proven to be a challenging task and respective reusability is less developed. Ontology reuse is expected to be a paramount activity for knowledge engineers, who in turn, are expected to reduce the cost of development and promote interoperability between applications. This is further intensified by the fact that many existing ontologies cover complementary and/or overlapping domains. Trokanas et al. (2016) presented a framework in the form of a set of metrics and a step-by-step procedure for evaluating compatibility of ontologies for ontology reuse, i.e., matching, aligning, merging, and integrating. This research presents an algorithm for the evaluation of ontologies for the purpose of reusing. For this, the algorithm relies on the ontology high-level information, which is readily available, easy to extract, and does not require any special expertise in ontology matching. This first attempt could be the foundation for further work on ontology evaluation and reuse leading to improved awareness in the community of process engineering.

As Remolona et al. (2017) highlighted, one of the most limiting factors for ontologies is that "properly populated" ontologies are scarce in most application domains. The other is that ontologies contain numerous concepts with enough connections, but they also rely on an extensive knowledge base. Creating this type of ontology requires tremendous investment of time, effort, and knowledge engineering for expert knowledge elicitation. To overcome this challenge, Remolona et al. (2017) presented a first attempt for an automation tool that can assist ontology engineers to quickly develop and organize domain specific ontologies. Their conceptual framework integrates machine learning and natural processing tasks: document sectioning, named entity recognition, concept detection, relation clustering, formula extraction, etc. While the results are encouraging, the experimental part of the study concludes that much more work must be performed to develop an automated ontology-based management system.

To qualify the different methods discussed in this perspective on process synthesis, we consider several criteria as presented in Table 3. The first criterion is the robustness of the method. Through this indicator, one can know if convergence can be obtained. It is difficult to decide when a problem is between the process and the molecular scale. For other cases, one can consider that if the problem is linear, due to the realized assumptions, one should obtain convergence with a reasonable computation time provided that the problem does not contain too many integer variables. For the method developed by Urselmann and Engell (2015), which is stochastic, one should obtain a result without being certain that the "slave" program converges at each iteration due to initialization problems, which should be different according to the envisaged conditions. The second criterion relates to the assumptions and uncertainties of the level considered. There are two main classes: those that "simplify" the problem and those that keep all the knowledge of the problem. Thus, the higher the level of the approach, the more important are the assumptions. The third criterion is the relevance of the results, which is strongly linked to the second criterion on hypotheses. If the assumptions are weak and convergence is obtained, the results can be considered relevant. The fourth criterion is the user ownership of the method. This criterion is generally easy or intermediate for researchers of the four methods. The fifth criterion is the possible application to different systems that could be proposed. For three of the four methods, the methodology is transferable to other studies with the same complexity. It is important to remember that this study should provide answers to future challenges of process engineering. The future challenges mentioned previously are

- biomass transformation as a chemical and energy feedstock replacing fossil fuels; 
- shale oil and gas as raw material for plastic production and associated future reorganization of the petrochemical industry;

- modular and distributed manufacturing using process intensification with flexibility approach; and

- response to spaceflight demands for Moon "cities" or the Mars exploration, in particular, the robustness and compactness of the process.

For the biorefinery concept, the paradigm changes from the conventional hydrocarbon-based refinery due to several bottlenecks. Among them, we can cite the complex thermodynamics of mixtures, high water content, and variety of organic molecules produced by bacteria. To compensate for the low efficiency of the fermentation step, the downstream process must be optimal and in the upstream, the supply chain must be considered. Therefore, in the biorefinery concept, all levels must be considered as much as possible. All six different scales, i.e., those described in Figure 1 and the supply chain and the molecular scales, must be integrated in the process design; interoperability will be an important challenge in the future.

Concerning shale oil and gas, the problem is different because most processes are already known; however, they must be adapted, and better integration both within the plant and in its immediate environment should be proposed.

In the present industrial context, with shorter product lifecycles, smaller production volumes, short time to market objectives, diversification, and increasing specialization of products due to more consumer-oriented product, development times and reconfiguration of production process times are becoming increasingly shorter. These trends will be enhanced further with the industry 4.0 evolution. Modular plants can be one promising response to address these challenges and aims, as they can increase flexibility in terms of capacity, product variation, and plant location. These new challenges will impact the synthesis and design of such plants. An efficient synthesis and design process can be performed by reusing data, information, and knowledge accumulated throughout all the project phases: construction, operation, dismantling, and module reuse. The main difference between classical and modular plant design is that the equipment and associated characteristics are known in early design stages for the latter. Thus, a key design task will involve adapting the individual process parameters for each unit operation and process equipment. The key is to propose new robust design methods and optimization strategies and to include flexibility as a main constraint for unit operation and plant design, while keeping process efficiency as high as possible. Process synthesis approaches will require new decision-making methods and tools for a structured equipment reconfigurability and flexibility evaluation, equipment comparison, and selection to cover the best possible operating conditions. Obviously, this will also have impacts on costs, and new ways of realizing quick and precise cost estimation will be required.

Spaceflight demands open new opportunities for process design (Chen and Grossmann, 2017) such as asteroid mining for precious compounds (some processing activities must be performed in space due to transportation costs), local processing for local human settlements, design of macro or nanoprocesses due to weight limitations in rocket technologies. Process modularity and flexibility for multipurpose processes will also require attention. "Infinite" recycling, i.e., a real circular use with zero waste of raw materials and resources to sustain habitable conditions and ensure viability is another challenge for process synthesis. Furthermore, the absence of gravity and especially its influence on the physical phenomena that occur in unit operations (intensified or conventional) will lead our community to review the operation of these units and invent new ones so that the physical and chemical phenomena can always be carried out efficiently. Therefore, the key parameter is innovation; the methodology will be concentrated on the process level with integration, and the PSE community must continue to develop computer-aided innovation software tools.

In addition to these future challenges, theoretical advances are also required. Obviously, the development of optimization methods and algorithms must continue to provide solutions to the global optimization problem. Either conventional or intensified unit operations require more detailed models to introduce small-scale phenomena, which influence the performance of unit operations. Such an approach leads to the introduction of multiscale information in the design process. Belletante et al. (2016) emphasized that multiscale approaches introduce more variables, equations, and constraints, and thus, result to more tremendous computational efforts. The development of methods to handle uncertainties is also a crucial challenge. During the process design stages via optimization approaches, hybrid approaches, or through metamodeling (multiparametric approach, "surrogate model," etc.), the introduction of inaccuracies and/or uncertainties on data is performed by local sensitivity studies or calculation of flexibility indices. In recent years, new methods of global sensitivity (e.g., Sobol method and chaos polynomials) have emerged, allowing the effective modeling and propagation of uncertainties in numerical simulation. Similarly, machine-learning methods have expanded considerably, for example, in the treatment of partitioning or discrimination problems. Furthermore, the modeling of poorly known data remains a major asset of the fuzzy logic. A possible strategy of renewing the methods for design processes could be the use of these three techniques, separated or combined, in order to reach more robust solutions that can allow inaccuracies/uncertainties inherent to the design stage, but at the same time, deal with hazards during process operation.

\section{References}

AACE International (2005) Cost estimate classification system As applied in engineering, procurement, and construction for the process industries (No. 18R-97).

Abou Elmaaty T.M., Kabeel A.E., Mahgoub M. (2017) Corrugated plate heat exchanger review, Renew. Sustain. Energy Rev. 70, 852-860. doi: 10.1016/j.rser.2016.11.266.

Ahmetović E., Ibrić N., Kravanja Z., Grossmann I.E. (2015) Water and energy integration: A comprehensive literature review of non-isothermal water network synthesis, Comput. 
Chem. Eng. 82, 144-171. doi: 10.1016/j.compchemeng.2015. 06.011.

Almeida-Rivera C.P., Swinkels P., Grievink J. (2004) Designing reactive distillation processes: Present and future, Comput. Chem. Eng. 28, 10, 1997-2020. doi: 10.1016/j.compchemeng. 2004.03.014.

Asadi E., Sadjadi S.J. (2017) Optimization methods applied to renewable and sustainable energy: A review, Uncertain Supply Chain Manag. 5, 1-26.

Babi D.K., Holtbruegge J., Lutze P., Gorak A., Woodley J.M., Gani R. (2015) Sustainable process synthesis-Intensification, Comput. Chem. Eng. 81, 218-244. doi: 10.1016/j.compchemeng. 2015.04.030.

Bagajewicz M. (2000) A review of recent design procedures for water networks in refineries and process plants, Comput. Chem. Eng. 24, 9-10, 2093-2113. doi: 10.1016/S0098-1354 (00)00579-2.

Bao B., Ng D.K.S., Tay D.H.S., Jiménez-Gutiérrez A., El-Halwagi M.M. (2011) A shortcut method for the preliminary synthesis of process-technology pathways: An optimization approach and application for the conceptual design of integrated biorefineries, Comput. Chem. Eng. 35, 8, 1374-1383. doi: 10.1016/j.compchemeng.2011.04.013.

Barbosa-Povoa A.P. (2017) A critical review on the design and retrofit of batch plants, Comput. Chem. Eng. 31, 833-855.

Barone D., Loth E., Snyder P. (2017) Influence of particle size on inertial particle separator efficiency, Powder Technol. 318, 177-185. doi: 10.1016/j.powtec.2017.04.044.

Bechara R., Gomez A., Saint-Antonin V., Schweitzer J.-M., Maréchal F. (2016a) Methodology for the design and comparison of optimal production configurations of first and first and second generation ethanol with power, Appl. Energy 184, 247-265. doi: 10.1016/j.apenergy.2016.09.100.

Bechara R., Gomez A., Saint-Antonin V., Schweitzer J.-M., Maréchal F. (2016b) Methodology for the optimal design of an integrated first and second generation ethanol production plant combined with power cogeneration, Bioresour. Technol. 214, 441-449. doi: 10.1016/j.biortech.2016.04.130.

Bechara R., Gomez A., Saint-Antonin V., Schweitzer J.-M., Maréchal F. (2016c) Methodology for the optimal design of an integrated sugarcane distillery and cogeneration process for ethanol and power production, Energy 117, 540-549. doi: 10.1016/j.energy.2016.07.018.

Belletante S., Montastruc L., Negny S., Domenech S. (2016) Optimal design of an efficient, profitable and sustainable biorefinery producing acetone, butanol and ethanol: Influence of the in-situ separation on the purification structure, Biochem. Eng. J. 116, 195-209. doi: 10.1016/j.bej.2016.05.004.

Benki A. (2014) Méthodes efficaces de capture de front de pareto en conception mécanique multicritère : applications industrielles, PhD Thesis, Université Sophia Antipolis.

Bertran M.-O., Frauzem R., Sanchez-Arcilla A.-S., Zhang L., Woodley J.M., Gani R. (2017a) A generic methodology for processing route synthesis and design based on superstructure optimization, Comput. Chem. Eng. 106, 892-910. doi: 10.1016/j.compchemeng.2017.01.030.

Bertran M.-O., Orsi A., Manenti F., Woodley J.M., Gani R. (2017b) Chapter 22 - Synthesis of sustainable biofuel processes: A generic methodology for superstructure optimization and data management, in: Kopanos G.M., Liu P., Georgiadis M.C. (eds), Advances in Energy Systems Engineering, Springer, pp. 651-681.
Bolliger R. (2010) Méthodologie de la synthèse des systèmes énergétiques industriels, PhD Thesis, EPFL, Lausanne.

Bolliger R., Maréchal F., Favrat D. (2005) Advanced power plant design methodology using process integration and multiobjectives thermo-economic optimisation, ECOS 2005, 18th International Conference on Efficiency, Cost, Optimization, Simulation and Environmental Impact of Energy Systems, Vol. 2, June 20-22, Trondheim, Norway.

Brandt S.C., Morbach J., Miatidis M., Theißen M., Jarke M., Marquardt W. (2008) An ontology-based approach to knowledge management in design processes, Comput. Chem. Eng. 32, 1-2, 320-342. doi: 10.1016/j.compchemeng.2007. 04.013 .

Celebi A.D., Ensinas A.V., Sharma S., Maréchal F. (2017) Earlystage decision making approach for the selection of optimally integrated biorefinery processes, Energy 137, 908-916. doi: 10.1016/j.energy.2017.03.080.

Chen Q., Grossmann I.E. (2017) Recent developments and challenges in optimization-based process synthesis, Ann. Rev. Chem. Biomol. Eng. 8, 249-283. doi: 10.1146/annurevchembioeng-080615-033546.

Chen Y., Adams T.A., Barton P.I. (2011a) Optimal design and operation of flexible energy polygeneration systems, Ind. Eng. Chem. Res. 50, 8, 4553-4566. doi: 10.1021/ie1021267.

Chen Y., Adams T.A., Barton P.I. (2011b) Optimal design and operation of static energy polygeneration systems, Ind. Eng. Chem. Res. 50, 9, 5099-5113. doi: 10.1021/ie101568v.

Corbetta M., Grossmann I.E., Manenti F. (2016) Process simulator-based optimization of biorefinery downstream processes under the Generalized Disjunctive Programming framework, Comput. Chem. Eng. 88, 73-85. doi: 10.1016/ j.compchemeng.2016.02.009.

Cremaschi S. (2015) A perspective on process synthesis: Challenges and prospects, Comput. Chem. Eng. 81, 130-137. doi: 10.1016/j.compchemeng.2015.05.007.

d'Anterroches L., Gani R. (2005) Group contribution based process flowsheet synthesis, design and modelling, Fluid Phase Equilib. 228-229, 141-146. doi: 10.1016/j.fluid.2004.08.018.

Ekşioğlu S.D., Acharya A., Leightley L.E., Arora S. (2009) Analyzing the design and management of biomass-to-biorefinery supply chain, Comput. Ind. Eng. 57, 4, 1342-1352. doi: 10.1016/j.cie.2009.07.003.

Fazlollahi S., Becker G., Ashouri A., Maréchal F. (2015) Multiobjective, multi-period optimization of district energy systems: IV - A case study, Energy 84, 365-381. doi: 10.1016/j. energy.2015.03.003.

Fazlollahi S., Becker G., Maréchal F. (2014a) Multi-objectives, multi-period optimization of district energy systems: II - Daily thermal storage, Comput. Chem. Eng. 71, 648-662. doi: 10.1016/j.compchemeng.2013.10.016.

Fazlollahi S., Bungener S.L., Mandel P., Becker G., Maréchal F. (2014b) Multi-objectives, multi-period optimization of district energy systems: I. Selection of typical operating periods, Comput. Chem. Eng. 65, 54-66. doi: 10.1016/j.compchemeng. 2014.03.005.

Fazlollahi S., Maréchal F. (2013) Multi-objective, multi-period optimization of biomass conversion technologies using evolutionary algorithms and mixed integer linear programming (MILP), Appl. Therm. Eng. 50, 2, 1504-1513. doi: 10.1016/j. applthermaleng.2011.11.035.

Fedorova M. (2015) Systematic methods and tools for computer aided modelling, Technical University of Denmark. 
Foo D.C.Y. (2009) State-of-the-art review of pinch analysis techniques for water network synthesis, Ind. Eng. Chem. Res. 48, 11, 5125-5159. doi: 10.1021/ie801264c.

Furman K.C., Sahinidis N.V. (2002) A critical review and annotated bibliography for heat exchanger network synthesis in the 20th century, Ind. Eng. Chem. Res. 41, 10, 2335-2370. doi: $10.1021 /$ ie010389e.

Gani R., Hytoft G., Jaksland C.A., Jensen A.K. (1997) An integrated computer aided system for integrated design of chemical processes, Comput. Chem. Eng. 21, 10, 1135-1146. doi: 10.1016/S0098-1354(96)00324-9.

Gani R., Nielsen B., Fredenslund A. (1991) A group contribution approach to computer-aided molecular design, AIChE J. 37, 9, 1318-1332. doi: 10.1002/aic.690370905.

Grossmann I.E. (1992) Mathematical methods for heat exchanger network synthesis, Carnegie Mellon University, Pittsburgh, PA.

Grossmann I.E., Daichendt M.M. (1996) New trends in optimization-based approaches to process synthesis, Comput. Chem. Eng. 20, 6/7, 665-683.

Gruber T.R. (1993) A translation approach to portable ontology specifications, Knowl. Acquis. 5, 199-220.

Gundersen T., Naess L. (1990) The synthesis of cost optimal heat exchanger networks, Heat Recover. Syst. CHP 10, 4, 301-328. doi: 10.1016/0890-4332(90)90084-W.

Hailemariam L., Venkatasubramanian V. (2010) Purdue ontology for pharmaceutical engineering: Part II. Applications, $J$. Pharm. Innov. 5, 4, 139-146. doi: 10.1007/s12247-010-9091-1.

Janus T., Foussette C., Urselmann M., Tlatlik S., Gottschalk A., Emmerich M., Bäck T, Engell S. (2017) Optimierungsbasierte Prozesssynthese auf Basis eines kommerziellen FlowsheetSimulators, Chem. Ing. Tech. 89, 5, 655-664. doi: 10.1002/ cite.201600179.

Kermani M., Périn-Levasseur Z., Benali M., Savulescu L., Maréchal F. (2017) A novel MILP approach for simultaneous optimization of water and energy: Application to a Canadian softwood Kraft pulping mill, Comput. Chem. Eng. 102, 238257. doi: 10.1016/j.compchemeng.2016.11.043.

Kokossis A.C., Labrador-Darder C., Cecelja F. (2016) Semantically enabled process synthesis and optimisation, Comput. Chem. Eng. 93, 64-86. doi: 10.1016/j.compchemeng.2016.05.018.

Kuznetsova E., Zio E., Farel R. (2016) A methodological framework for Eco-Industrial Park design and optimization, $J$. Clean. Prod. 126, 308-324. doi: 10.1016/j.jclepro.2016.03.025.

Le Cun Y., Bengio Y., Hinton G. (2015) Deep learning, Nature 5, 21, 436-444.

Lee J.H., Shin J., Realff M.J. (2018) Machine learning: Overview of the recent progresses and implications for the process systems engineering field, Comput. Chem. Eng. 114, 111-121.

Li X., Kraslawski A. (2004) Conceptual process synthesis: Past and current trends, Chem. Eng. Process. Process Intensif. 43, 5, 583-594. doi: 10.1016/j.cep.2003.05.002.

López-Arévalo I., Bañares-Alcántara R., Aldea A., RodríguezMartínez A., Jiménez L. (2007) Generation of process alternatives using abstract models and case-based reasoning, Comput. Chem. Eng. 31, 8, 902-918. doi: 10.1016/ j.compchemeng.2006.08.011.

Maronese S. (2014) Optimum biorefinery pathways selection using MILP with integer-cuts constraint method, Thesis, Università degli Studi di Padova, Laurea Magistrale.

Maronese S., Ensinas A.V., Mian A., Lazzaretto A., Maréchal F. (2015) Optimum biorefinery pathways selection using the integer-cuts constraint method applied to a MILP problem,
Ind. Eng. Chem. Res. 54, 28, 7038-7046. doi: 10.1021/acs. iecr.5b01439.

Marrero J., Gani R. (2001) Group-contribution based estimation of pure component properties, Fluid Phase Equilib. 183-184, 183-208. doi: 10.1016/S0378-3812(01)00431-9.

Morar M., Agachi P.S. (2010) Review: Important contributions in development and improvement of the heat integration techniques, Comput. Chem. Eng. 34, 8, 1171-1179. doi: 10.1016/j.compchemeng.2010.02.038.

Morbach J., Wiesner A., Marquardt W. (2009) OntoCAPE - A (re)usable ontology for computer-aided process engineering, Comput. Chem. Eng. 33, 10, 1546-1556. doi: 10.1016/ j.compchemeng.2009.01.019.

Morbach J., Yang A., Marquardt W. (2007) OntoCAPE - A large-scale ontology for chemical process engineering, Eng. Appl. Artif. Intell. 20, 2, 147-161. doi: 10.1016/j.engappai.2006. 06.010 .

Morelos K.P., Mass A.B., Vergara F.G., Gonzalez-Delgado D. (2015) Development of a hybrid methodology for the synthesis of biofuels production processes based on optimization of superstructures, Chem. Eng. Trans. 43, 349-354.

Muñoz E., Capón-García E., Laínez J.M., Espuña A., Puigjaner L. (2013) Integration of enterprise levels based on an ontological framework, Chem. Eng. Res. Des. 91, 8, 15421556. doi: 10.1016/j.cherd.2013.04.015.

Muñoz E., Espuña A., Puigjaner L. (2010) Towards an ontological infrastructure for chemical batch process management, Comput. Chem. Eng. 34, 5, 668-682. doi: 10.1016/ j.compchemeng.2009.12.009.

Natarajan S., Ghosh K., Srinivasan R. (2012) An ontology for distributed process supervision of large-scale chemical plants, Comput. Chem. Eng. 46, 124-140. doi: 10.1016/j.compchemeng. 2012.06.009.

Ni J., Yi J., Ni S. (2011) A practical development of knowledge management model for petrochemical product family, in: 2011 International Conference on Information Management, Innovation Management and Industrial Engineering, 26-27 November, Shenzhen, China, pp. 197-200.

Ochoa-Estopier L., Jobson M., Smith R. (2013) Operational optimization of crude oil distillation systems using artificial neural networks, Comput. Chem. Eng. 59, 178-185.

Omidi M., Farhadi M., Jafari M. (2017) A comprehensive review on double pipe heat exchangers, Appl. Therm. Eng. 110, 1075-1090. doi: 10.1016/j.applthermaleng.2016.09.027.

Palazzi F., Périn-Levasseur Z., Bolliger R., Gassner M. (2010) OSMOSE - User manual.

Pham V., El-Halwagi M.M. (2012) Process synthesis and optimization of biorefinery configurations, AIChE J. 58, 4, 1212-1221. doi: 10.1002/aic.12640.

Pinto-Varela T., Carvalho A.I. (2018) Handbook of green chemistry, Sustainable Design of batch processes, WileyVCH, Weinheim, Germany, Vol. 11, pp. 125-156. Chapt. 5.

Poe W.A., Mokhatab S. (2016) Process optimization, in: Poe W.A. (ed), Modeling, Control, and Optimization of Natural Gas Processing Plants, 1st edn., Elsevier, Cambridge, MA, pp. 173-213.

Ponce-Ortega J.M., Pham V., El-Halwagi M.M., El-Baz A.A. (2012) A disjunctive programming formulation for the optimal design of biorefinery configurations, Ind. Eng. Chem. Res. 51, 8, 3381-3400. doi: 10.1021/ie201599m.

Ramos M., Boix M., Aussel D., Montastruc L., Domenech S. (2016) Optimal design of water exchanges in eco-industrial parks through a game theory approach, in: Kravanja Z. (ed), 
Computer Aided Chemical Engineering, 26th European Symposium on Computer Aided Process Engineering, Elsevier Science, Amsterdam, The Netherlands, pp. 1177-1182.

Reklaitis G.V. (1989) Progress and issues in computer aided batch process design, in: Third International Conference on Foundations of Computers Aided Process Design (FOCAPD), pp. 241-276.

Remolona M.F.M., Conway M.F., Balasubramanian S., Fan L., Feng Z., Gu T., Kim H., Nirantar P.M., Panda S., Ranabothu N.R., Rastogi N., Venkatasubramanian V. (2017) Hybrid ontology-learning materials engineering system for pharmaceutical products: Multi-label entity recognition and concept detection, Comput. Chem. Eng. 107, 49-60. doi: 10.1016/ j.compchemeng.2017.03.012.

Roy R., Hinduja S., Teti R. (2008) Recent advances in engineering design optimisation: Challenges and future trends, CIRP Ann. Manuf. Technol. 57, 2, 697-715. doi: 10.1016 j.cirp.2008.09.007.

Segovia-Hernández J.G., Hernández S., Bonilla Petriciolet A. (2015) Reactive distillation: A review of optimal design using deterministic and stochastic techniques, Chem. Eng. Process. Process Intensif. 97, 134-143. doi: 10.1016/j.cep. 2015.09.004.

Stephanopoulos G., Reklaitis G.V. (2011) Process systems engineering: From Solvay to modern bio- and nanotechnology: A history of development, successes and prospects for the future, Chem. Eng. Sci. 66, 19, 4272-4306.

Tay D.H., Ng D.K., Tan R.R. (2013) Robust optimization approach for synthesis of integrated biorefineries with supply and demand uncertainties, Environ. Progr. Sustain. Energy 32, 2, 384-389. doi: 10.1002/ep.10632.

Trokanas N., Bussemaker M., Cecelja F. (2016) Utilising semantics for improved decision making in bio-refinery value chains, in: Kravanja Z. (ed), Computer Aided Chemical Engineering, 26th European Symposium on Computer Aided Process Engineering, Elsevier Science, Amsterdam, The Netherlands, pp. 2097-2102.

Tula A.K., Babi D.K., Bottlaender J., Eden M.R., Gani R. (2017) A computer-aided software-tool for sustainable process synthesis-intensification, Comput. Chem. Eng. 105, 74-95. doi: 10.1016/j.compchemeng.2017.01.001.

Tula A.K., Eden M.R., Gani R. (2015) Process synthesis, design and analysis using a process-group contribution method, Comput. Chem. Eng. 81, 245-259. doi: 10.1016/j.compchemeng. 2015.04.019.

Urselmann M., Engell S. (2015) Design of memetic algorithms for the efficient optimization of chemical process synthesis problems with structural restrictions, Comput. Chem. Eng. 72, 87-108. doi: 10.1016/j.compchemeng.2014.08.006.

Urselmann M., Foussette C., Janus T. (2016) Selection of a DFO method for the efficient solution of continuous constrained sub-problems within a memetic algorithm for chemical process synthesis, Genetic and Evolutionary Conference (GECCO), Denver, Colorado, USA, July 20-24, 2016.

Venkatasubramanian V. (2009) Drowing in data: Informatics and modeling challenges in a data-rich networked world, AIChE J. 55, 1, 2-8. doi: 10.1002/aic.11756.

Venkatasubramanian V., Zhao C., Joglekar G., Jain A., Hailemariam L., Suresh P., Akkisetty P., Morris K., Reklaitis G.V. (2006) Ontological informatics infrastructure for pharmaceutical product development and manufacturing, Comput. Chem. Eng. 30, 10-12, 1482-1496. doi: 10.1016/j.compchemeng.2006.05.036.

Westerberg A.W. (2004) A retrospective on design and process synthesis, Comput. Chem. Eng. 28, 4, 447-458. doi: $10.1016 /$ j.compchemeng.2003.09.029.

Wu W., Henao C.A., Maravelias C.T. (2016) A superstructure representation, generation, and modeling framework for chemical process synthesis, AIChE J. 62, 9, 3199-3214. doi: $10.1002 /$ aic. 15300.

Xia W. (2017) Role of particle shape in the floatability of mineral particle: An overview of recent advances, Powder Technol. 317, 104-116. doi: 10.1016/j.powtec.2017.04.050.

Yildirim Ö., Kiss A.A., Kenig E.Y. (2011) Dividing wall columns in chemical process industry: A review on current activities, Sep. Purif. Technol. 80, 3, 403-417. doi: 10.1016/j. seppur.2011.05.009.

Yuan Z., Chen B., Gani R. (2013) Applications of process synthesis: Moving from conventional chemical processes towards biorefinery processes, Comput. Chem. Eng. 49, 217229. doi: 10.1016/j.compchemeng.2012.09.020.

Zhao Q., Neveux T., Mecheri M., Privat R., Guittard P., Jaubert J.-N. (2018) Superstructure optimization (MINLP) within ProSimPlus simulator, 28th European Symposium on Computer Aided Process Engineering, pp. 767-772.

Zhou L., Pan M., Sikorski J.J., Garud S., Aditya L.K., Kleinelanghorst M.J., Karimi I.A., Kraft M. (2017) Towards an ontological infrastructure for chemical process simulation and optimization in the context of eco-industrial parks, Appl. Energy 204, 1284-1298. doi: 10.1016/j.apenergy.2017.05.002.

Zondervan E., Nawaz M., de Haan A.B., Woodley J.M., Gani R. (2011) Optimal design of a multi-product biorefinery system, Comput. Chem. Eng. 35, 9, 1752-1766. doi: 10.1016/ j.compchemeng.2011.01.042. 


\section{Appendix A}

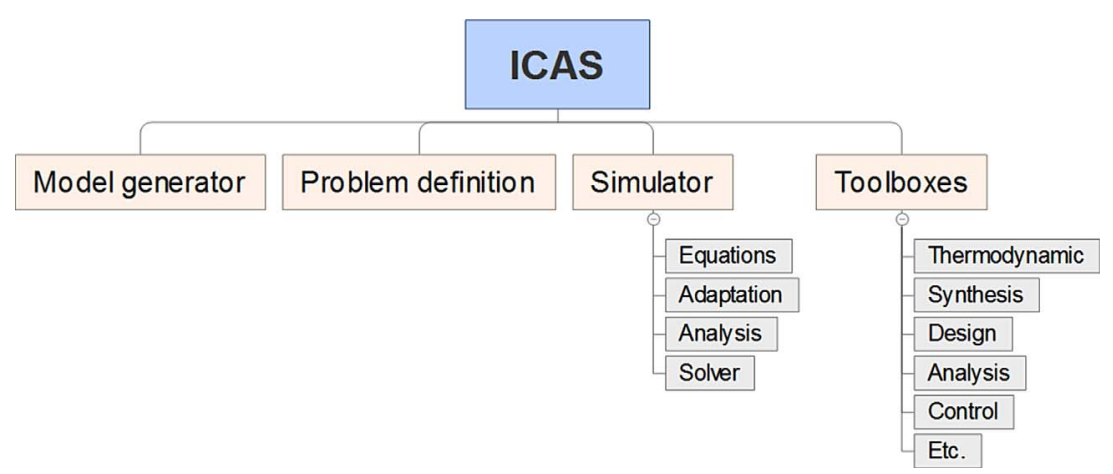

Fig. A1. Main structure of ICAS (inspired by Gani et al., 1997).

\section{Appendix B}

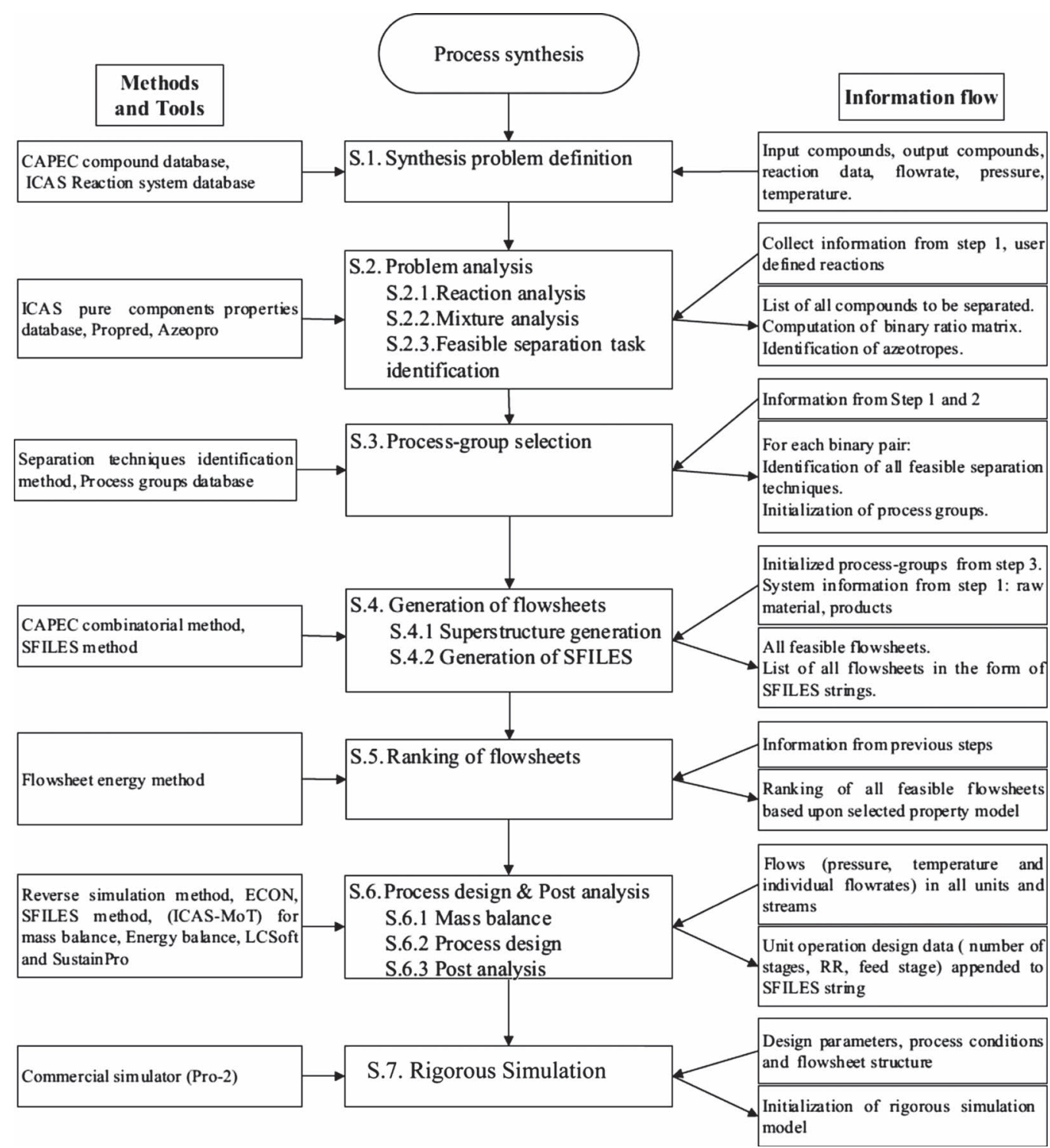

Fig. B1. Methodology using ICAS (adapted from Tula et al., 2015). 


\section{Appendix C}

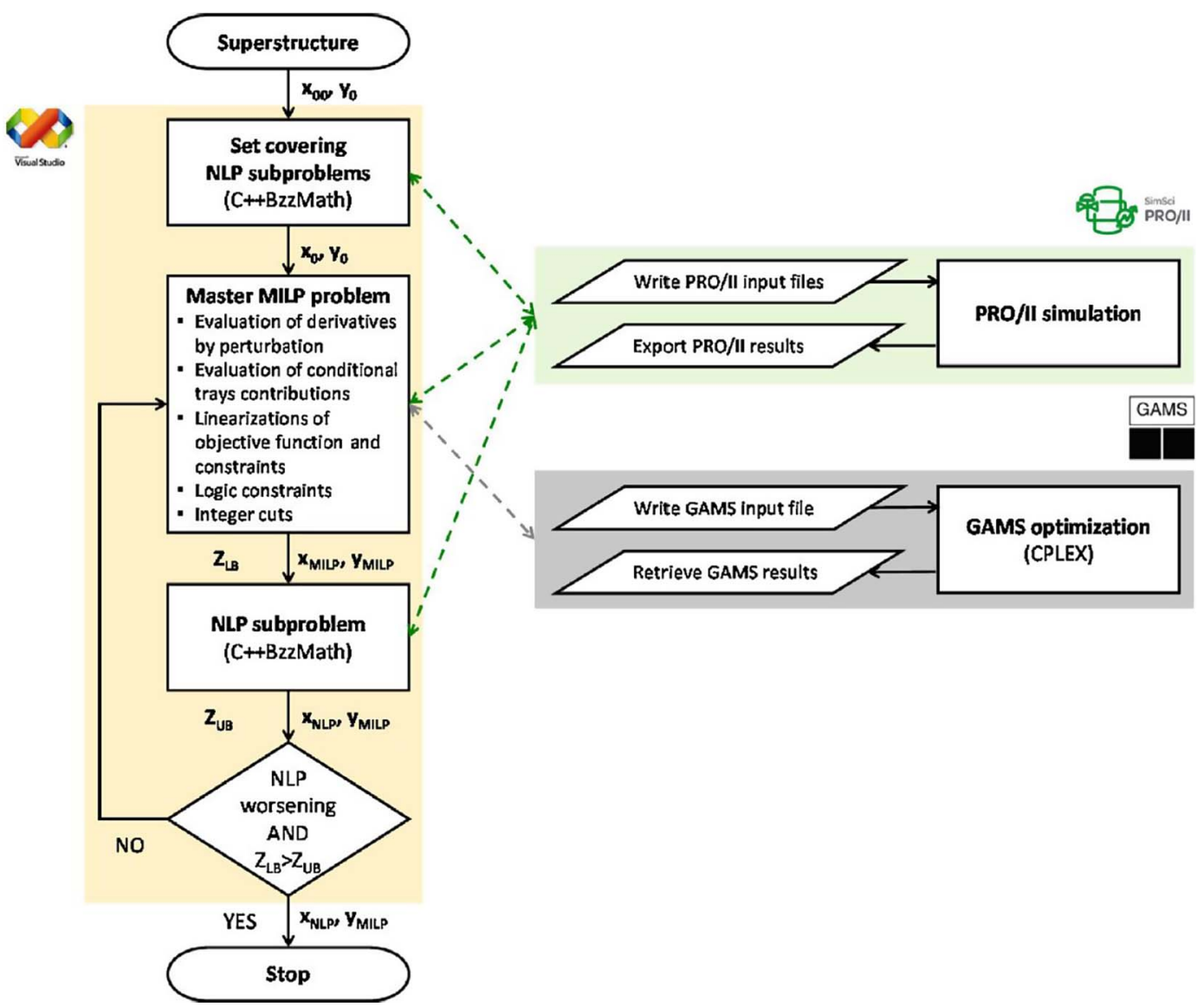

Fig. C1. Optimization algorithm block diagram (adapted from Corbetta et al., 2016).

\section{Appendix D}

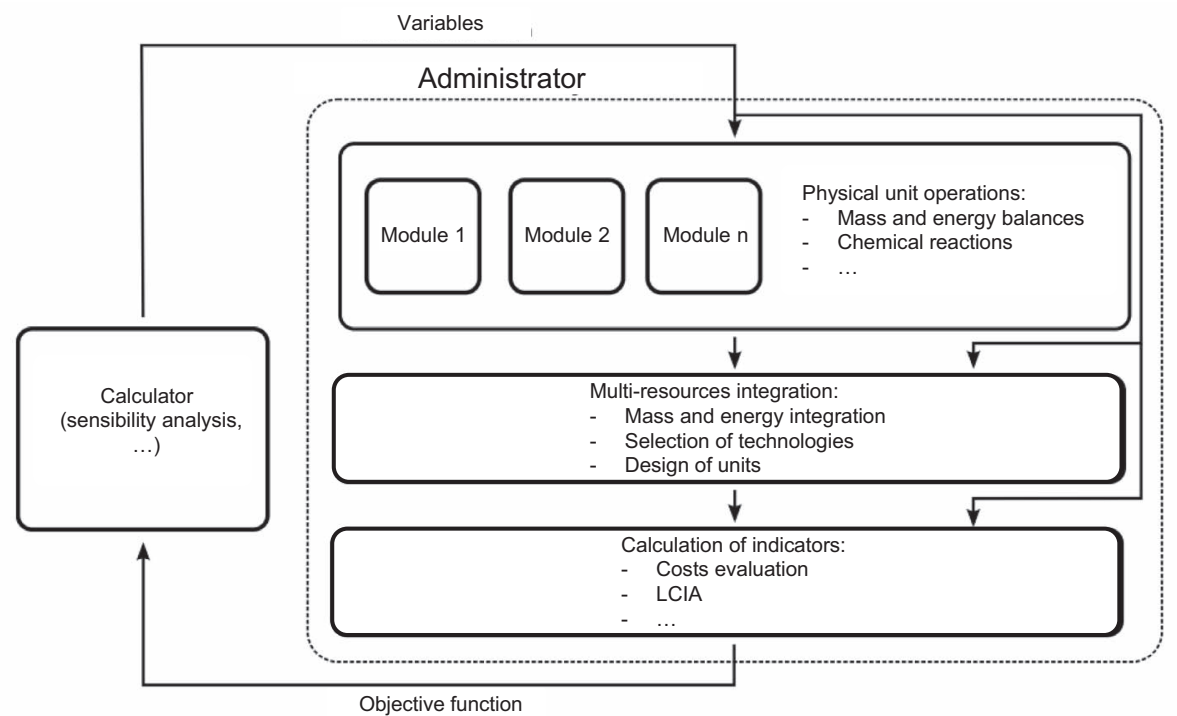

Fig. D1. Structure of OSMOSE platform (adapted from Bolliger, 2010). 


\section{Appendix E}

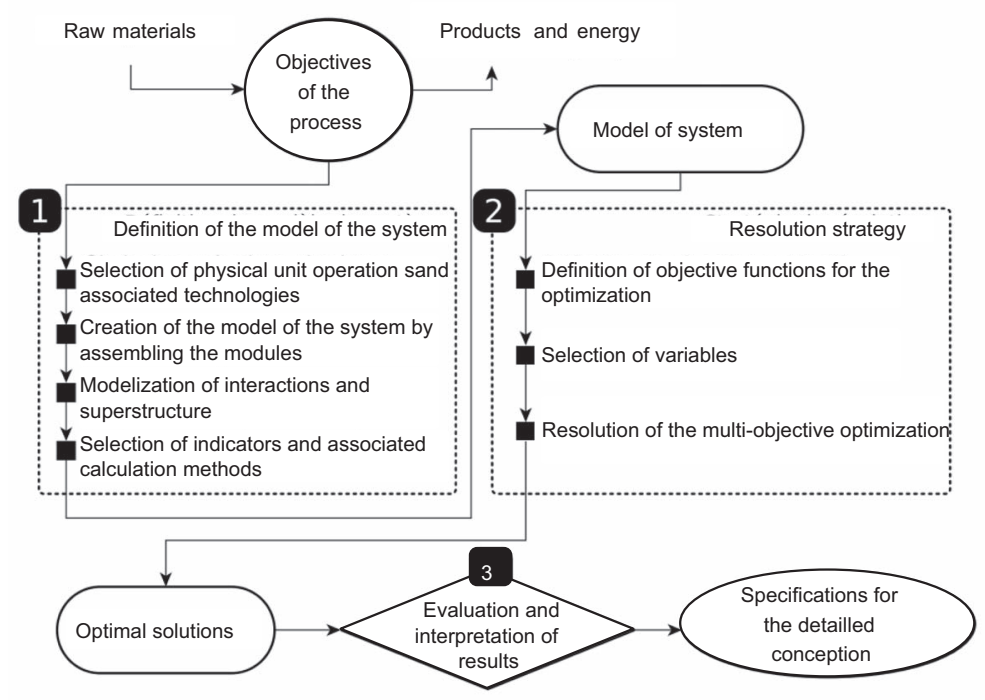

Fig. E1. Example of methodology using OSMOSE platform (adapted from Bolliger, 2010).

\section{Appendix F}

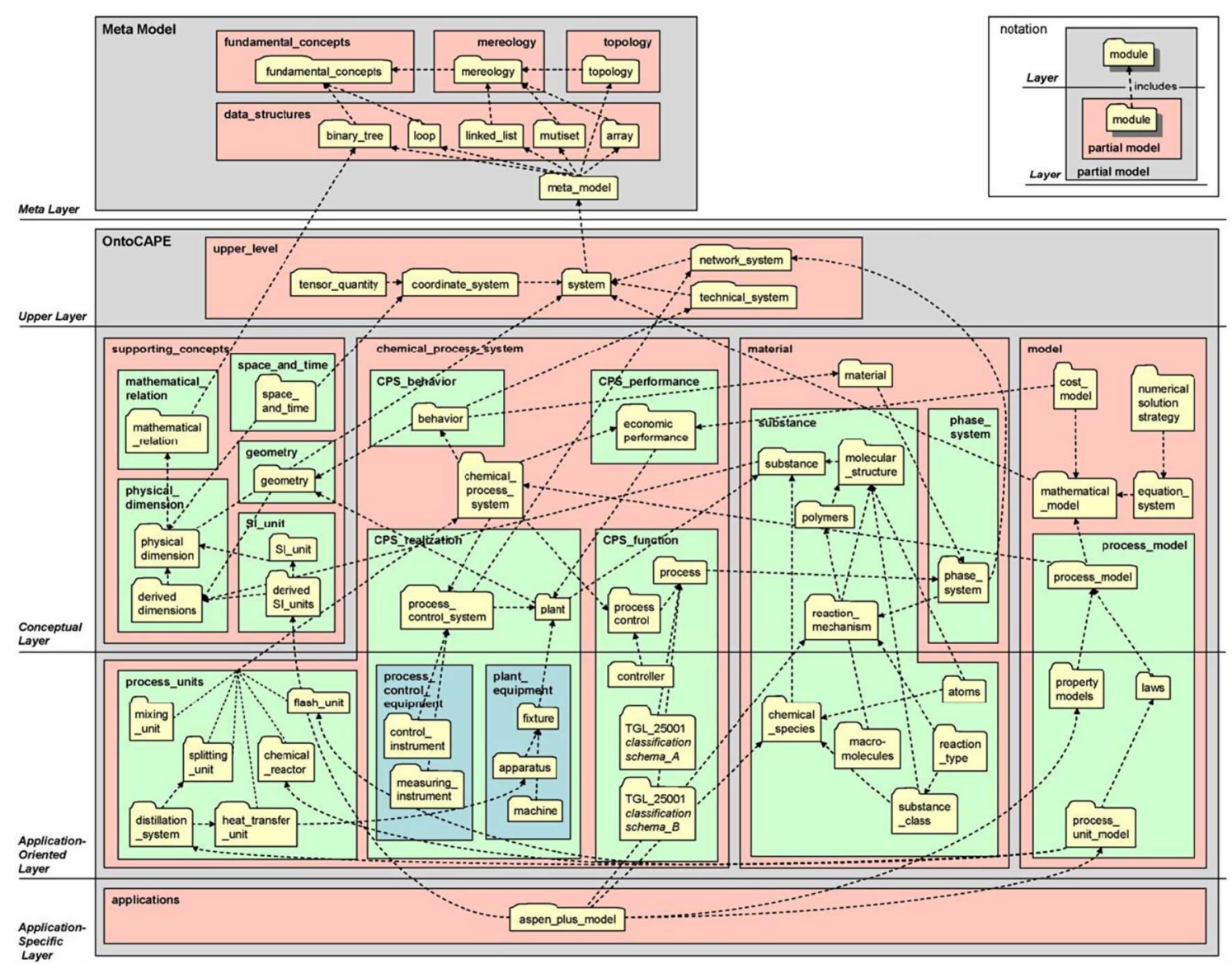

Fig. F1. Structure of OntoCAPE (adapted from Morbach et al., 2009). 